Published in final edited form as:

J Proteome Res. 2016 February 5; 15(2): 374-388. doi:10.1021/acs.jproteome.5b00946.

\title{
Elucidating the Molecular Composition of Cartilage by Proteomics
}

\author{
Ming-Feng Hsueh ${ }^{1,3}$, Areej Khabut ${ }^{4}$, Sven Kjellström ${ }^{5}$, Patrik Önnerfjord ${ }^{4}$, and Virginia \\ Byers Kraus ${ }^{*}, 1,2$ \\ ${ }^{1}$ Duke Molecular Physiology Institute, Duke University School of Medicine, Duke University, \\ Durham, NC 27701 \\ ${ }^{2}$ Department of Medicine Duke University School of Medicine, Duke University, Durham, NC \\ 27701 \\ 3Department of Pathology, Duke University School of Medicine, Duke University, Durham, NC \\ 27701 \\ ${ }^{4}$ Department of Clinical Sciences Lund, Section of Rheumatology and Molecular Skeletal Biology, \\ Lund University, Lund, Sweden \\ ${ }^{5}$ Department of Biochemistry and Structural Biology, Center for Molecular Protein Science, Lund \\ University, Lund, Sweden
}

\begin{abstract}
Articular cartilage consists of chondrocytes and two major components, a collagen-rich framework and highly abundant proteoglycans. Most prior studies defining the zonal distribution of cartilage have extracted proteins with guanidine-HCl. However, an unextracted collagen-rich residual is left after extraction. In addition, the high abundance of anionic polysaccharide molecules extracted from cartilage adversely affects the chromatographic separation. In this study, we established a method for removing chondrocytes from cartilage sections with minimal extracellular matrix protein loss. The addition of surfactant to guanidine- $\mathrm{HCl}$ extraction buffer improved protein solubility. Ultrafiltration removed interference from polysaccharides and salts. Almost four times more collagen peptides were extracted by the in situ trypsin digestion method. However, as expected, proteoglycans were more abundant within the guanidine- $\mathrm{HCl}$ extraction. These different methods were used to extract cartilage sections from different cartilage layers (superficial, intermediate and deep), joint types (knee and hip), and disease states (healthy and osteoarthritic)
\end{abstract}

Correspondence can be sent to: Virginia Byers Kraus, MD, PhD, Box 104775, Duke Molecular Physiology Institute, 300 North Duke St., Durham, NC 27701, Phone: 919-681-6652, Fax: 919-684-8907, vbk@ duke.edu.

Author contributions

M-FH, AK, PÖ and VBK were involved in the conception and design of the study as well as the interpretation of the data. MF-H, AK and PÖ conducted the experimental work and targeted mass spectrometry experiments. SK and PÖ conducted the discovery mass spectrometry experiments. All authors critically revised the article, VBK (corresponding author, E-mail: vbk@ duke.edu) gave final approval of the article.

Supporting information

This material is available free of charge via the internet, http://pubs.acs.org

Competing interest statement

The authors have no conflict of interest of any kind with regard to this work. 
and the extractions were evaluated by quantitative and qualitative proteomic analyses. The results of this study led to the identifications of the potential biomarkers of OA, OA progression, and the joint specific biomarkers.

\section{TOC Graphic}

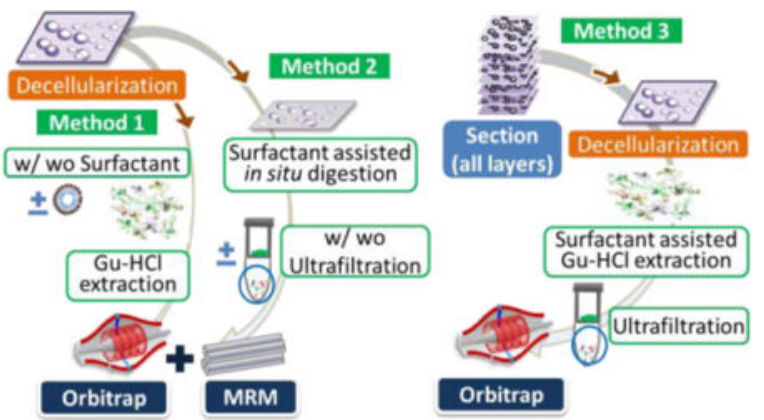

\section{Keywords}

Cartilage; Extracellular matrix proteins; Proteomics; Multiple Reaction Monitoring; Guanidine$\mathrm{HCl}$ extraction; in situ trypsin digestion

\section{Introduction}

Articular cartilage has unique physical and mechanical properties conveyed by chondrocytes and the extracellular matrix (ECM), consisting predominantly of collagens, proteoglycans, hyaluronic acid, and other important but low abundance non-collagenous proteins ${ }^{1-3}$. Fibrillar type II collagen form the basic framework structure of cartilage tissue with copolymerized type XI collagen and surface cross-linked type IX collagen ${ }^{4}$ while type IX collagen is cross-linked to the type II collagen fibril via aldimine-derived crosslinks ${ }^{5}$. This highly cross-linked framework usually remains intact even after extraction. Non-fibrillar type VI collagen surrounds the chondrocytes and may facilitate chondrocyte-matrix interactions $^{6-9}$. Proteoglycans, consisting predominately of aggrecan, attract water and create large, hydrated spaces in the ECM of cartilage. This characteristic provides the durability to compression generated during movement. A variety of non-collagenous proteins help to assemble and stabilize the extracellular matrix e.g. by cross-bridging of collagen fibers. To holistically understand the properties of articular cartilage, it is necessary to appreciate its composition by its layers (superficial, intermediate, and deep layers by distance from the surface), and subregions (pericellular, territorial, and interterritorial regions by distance from the chondrocyte), as well as various chondrocyte phenotypes ${ }^{10}$. To effectively characterize these various components, it is necessary to develop an effective method for conducting differential proteomics on cartilage.

The commonly used guanidine- $\mathrm{HCl}$ method extracts strong non-covalently bound $\mathrm{ECM}$ proteins and cellular proteins simultaneously from cartilage tissue ${ }^{11-14}$ and leaves unextracted, a substantial amount of a collagen-rich residue. Therefore, it is not suitable for evaluating proteins forming the collagen framework. For instance, guanidine- $\mathrm{HCl}$ has been 
shown to extract $90 \%$ of the available aggrecan, asporin, and decorin but only $10 \%$ of the collagen content ${ }^{14}$. Even cartilage treatment with $2 \%$ SDS for 8 hours is insufficient for extracting collagen ${ }^{15}$. Generally, the investigation of the insoluble residue has focused on the major components such as collagens and glycosaminoglycans ${ }^{16}$. However, the composition of the insoluble collagen-rich residue from highly cross-linked cartilage tissues has not been fully elucidated. Past studies evaluating the zonal specificity of cartilage proteins have generally focused on only one or two cartilage components ${ }^{17-19}$. Only a few studies have utilized proteomic methodology to more comprehensively evaluate cartilage $\mathrm{e}^{20-22}$.

Past proteomic studies of cartilage focus on whole cartilage tissue; results therefore reflect both the intracellular and the extracellular proteome. Although studies of other collagenabundant tissues, such as the heart and pulmonary tissue, have successfully analyzed decellularized tissue ${ }^{23-25}$, this methodology has not been utilized in proteomic studies of cartilage. This may in part, be due to the relative sparsity of chondrocytes in cartilage and a perception that they contribute minimally to the tissue proteome by virtue of the lesser amount of protein contributed by the cells relative to the total protein contributed by the ECM. Although sparse, their contribution may be quite significant when evaluating highly localized regions of interest, such as the territorial region of the ECM. In addition, cartilage decellularization may have been ignored to date due to difficulties eliminating chondrocytes without significantly impacting the ECM.

Our goal was to develop methods of cartilage extraction for proteomic analysis that would allow a holistic characterization of the various cartilage components, so-called differential proteomics. This required dealing with the challenges of the overwhelming abundance of the two major constituents of cartilage, collagen and aggrecan that obscure the identification of other less abundant proteins. This also required exploring methods to analyze the highly cross-linked collagen components and dealing with the anionic polysaccharide molecules, such as hyaluronan, chondroitin sulfate, and keratan sulfate that affect the chromatographic separation. Finally, the method had to be suitable for the common situations of restricted amounts of cartilage available for analysis, often less than $1 \mathrm{~g}$ of material or even as little as milligram quantities for regional analyses. In this work, we developed a reproducible method for decellularizing cartilage with minimal impact on the ECM. Applying this method to serial transverse cartilage sections, we were able to map the cartilage zonal compositions of matrix proteins in different joints (knees and hips) as well as different pathological conditions. To our knowledge, this is the first study of the ECM specific proteome at different depths in human articular cartilage from different joints and physiological conditions.

\section{Materials and Methods}

\section{Clinical cartilage specimen sources}

Perilesional articular cartilage specimens from hip and knee joints were obtained from patients with OA who had arthroplasties performed at Duke University Medical Center. Healthy non-OA cartilage specimens were collected at the time of surgery for acute trauma from patients; absence of OA was determined by the surgeon and confirmed by macroscopic inspection upon acquisition of the sample in the laboratory. All samples were collected 
under Duke Institutional Review Board approval as waste surgical specimens. Cartilage specimens were frozen and stored at $-80^{\circ} \mathrm{C}$. Specimens were embedded in Tissue-Tek O.C.T. (Sakura, The Netherlands) for cryosectioning. Serial transverse frozen sections of $12 \mu \mathrm{m}$ thickness were generated at different depths from the cartilage surface. The first 20 sections were collected and categorized as representing the superficial layer. The subsequent 20 sections were skipped, then 20 collected to represent the intermediate layer, 20 again skipped and the 20 subsequent sections collected to represent the deep layer.

\section{Decellularization}

To eliminate chondrocyte protein interference in the ECM proteomic analysis, we developed a procedure to separate the ECM and chondrocytes. The optimized procedure relies on depletion of chondrocytes from frozen tissue sections based on their sensitivity to hypoosmotic pressure and ice crystal formation. A $12 \mu \mathrm{m}$ thick frozen tissue section on a glass slide (VWR, Radnor, PA) was immersed in hypotonic solution (deionized $\mathrm{H}_{2} \mathrm{O}$ ) sufficient to cover the section; it subsequently underwent rapid freeze/slow thaw cycles (the slide was placed on a metal pad, which directly contacted dry ice followed by thawing at room temperature) for a total of four cycles. The hypotonic solution was exchanged and collected after each cycle and analyzed for double stranded DNA, glycosaminoglycans (GAGs) and total protein, to monitor the effect of the decellularization procedure. This method also resulted in removal of the aqueous embedding medium.

\section{Monitoring the effect of decellularization}

Double-stranded DNA was quantified by Qubit ${ }^{\circledR}$ dsDNA HS kit per the manufacturer's instructions (Life technologies, Grand Island, NY). The glycosaminoglycan concentration was measured by 1,9-dimethylmethylene blue (DMMB) assay as described previously ${ }^{26}$. Protein concentration within the supernatant was determined by bicinchoninic acid (BCA) assay per the manufacturer's instructions (Thermo, Waltham, WA).

\section{Cartilage protein extraction by guanidine- $\mathrm{HCl}$ method}

Cartilage protein extraction and preparation for mass spectrometric analyses were performed as previously described ${ }^{20}$. Briefly, frozen cartilage sections were extracted using guanidine extraction buffer (4 M guanidine- $\mathrm{HCl}, 50 \mathrm{mM}$ sodium acetate, $100 \mathrm{mM}$ 6-aminocaproic acid, $5 \mathrm{mM}$ benzamidine, $5 \mathrm{mM}$ N-ethylmaleimide, $\mathrm{pH} 5.8$ ) for $24 \mathrm{~h}$ on an orbital shaker at $4^{\circ} \mathrm{C}$. Extracts were collected after centrifugation at $13,200 \mathrm{~g}$ at $4^{\circ} \mathrm{C}$ for 30 minutes. The pellet (extraction residue) was washed once with ammonium bicarbonate (AmBic) buffer and this AmBic solution was combined with the extracted fractions for complete quantification of cartilage components. In addition to the conventional extraction methods, we also tested a combination of $0.2 \%$ RapiGest (Waters Corporation, Milford, MA) in $50 \mathrm{mM}$ AmBic, $\mathrm{pH} 8.5$ with guanidine- $\mathrm{HCl}$ buffer. The sample preparation and workflow are illustrated in Figure 3A (method 1)

\section{Cartilage protein extraction by in situ trypsin digestion method}

Cartilage tissue sections (the representative adjacent sections and extraction residue) were immersed in $0.2 \%$ RapiGest (Waters Corporation, Milford, MA) in 50mM AmBic, pH 8.5 
and heated to $37^{\circ} \mathrm{C}$ for 10 minutes. Treated tissue sections were further processed for mass spectrometry analysis. The sample preparation and workflow are illustrated in Figure 3A (method 2).

\section{Sample preparation for mass spectrometry analysis}

The $100 \mu$ guanidine- $\mathrm{HCl}$ extracts and processed sections were reduced with $4 \mathrm{mM}$ DTT at $56^{\circ} \mathrm{C}$ for 30 minutes on an orbital shaker and alkylated with $16 \mathrm{mM}$ iodoacetamide at room temperature for $1 \mathrm{~h}$ in the dark. The $\mathrm{Gu}-\mathrm{HCl}$ extracts were precipitated with ethanol (9:1) overnight at $4^{\circ} \mathrm{C}$ and collected after centrifugation at $13,200 \mathrm{~g}$ at $4^{\circ} \mathrm{C}$ for 30 minutes. The pellets were washed with ethanol for $4 \mathrm{~h}$ at $-20^{\circ} \mathrm{C}$ to remove residual salts. Samples were dried in a SpeedVac and suspended in $100 \mu \mathrm{l}$ of $0.1 \mathrm{M}$ AmBic, $\mathrm{pH}$ 8.5. Trypsin digestion was performed with $2 \mu \mathrm{g}$ of trypsin gold (Promega, Madison, WI) at $37^{\circ} \mathrm{C}$ on a shaker for $16 \mathrm{~h}$ for both $\mathrm{Gu}-\mathrm{HCl}$ extracts and processed sections. Subsequently, samples were diluted to $200 \mu \mathrm{l}$ with 0.5M AmBic and filtered through a 30kDa filter (Pall Life Sciences, Port Washington, NY) by centrifugation at $2060 \times \mathrm{g}$ for 8 minutes. The filter was then washed with an additional $100 \mu 10.5 \mathrm{M}$ AmBic buffer to optimize recovery. To test the effects of removing residual polysaccharides and salts, the filtrates were then processed with and without ultrafiltration through a reversed-phase C18 column (The Nest group, Southborough, MA) according to the manufacturer's instructions.

\section{Non-targeted and targeted mass spectrometry}

Non-targeted mass spectrometry experiments were performed with an EasyLC nanoflow high-performance liquid chromatography (HPLC) (Proxeon Biosystems, Odense, Denmark) connected to a LTQ-Orbitrap Velos Pro mass spectrometer (Thermo Fisher Scientific, Waltham, WA) equipped with a nanoEasy spray ion source (Proxeon Biosystems, Odense, Denmark). The chromatographic separation was performed at $40^{\circ} \mathrm{C}$ on a $15 \mathrm{~cm}(75 \mu \mathrm{m}$ i.d.) EASY-Spray column packed with $3 \mu \mathrm{m}$ resin (Proxeon Biosystems, Odense, Denmark). The nanoHPLC intelligent flow control gradient was 5-20\% solvent B (0.1\% (v/v) FA, 100\% $(\mathrm{v} / \mathrm{v})$ acetonitrile in water) in solvent $\mathrm{A}(0.1 \%(\mathrm{v} / \mathrm{v}) \mathrm{FA}$ in water), for $120 \mathrm{~min}$, and then $20 \%-40 \%$ for $60 \mathrm{~min}$ followed with an increase to $90 \%$ for $5 \mathrm{~min}$. A flow rate of $300 \mathrm{nl} / \mathrm{min}$ was used through the whole gradient. An MS scan $(400-1400 \mathrm{~m} / \mathrm{z}$ ) was recorded in the Orbitrap mass analyzer set at a resolution of 60,000 at $400 \mathrm{~m} / \mathrm{z}, 1 \times 10^{6}$ automatic gain control target and $500 \mathrm{~ms}$ maximum ion injection time. The MS was followed by datadependent collision-induced dissociation MS/MS scans on the eight most intense multiply charged ions in the LTQ at 500 signal threshold, $3 \mathrm{~m} / \mathrm{z}$ isolation width, $10 \mathrm{~ms}$ activation time at 35 normalized collision energy and dynamic exclusion enabled for 60 seconds. The general mass spectrometric conditions were as follows: spray voltage, $2.0 \mathrm{kV}$; no sheath or auxiliary gas flow; S-lens $60 \%$; ion transfer tube temperature, $275^{\circ} \mathrm{C}$.

The effect of cartilage section decellularization was evaluated by non-targeted mass spectrometry experiments performed on a quadrupole Orbitrap benchtop mass spectrometer (Q-Exactive) (Thermo Fisher Scientific, Waltham, WA) equipped with an Easy nano-LC 1000 system (Thermo Scientific, Waltham MA). Separation was performed on $75 \mu \mathrm{m} \times 25$ $\mathrm{cm}$ capillary columns (Acclaim Pepmap ${ }^{\mathrm{TM}} \mathrm{RSLC}, \mathrm{C} 18,2 \mu \mathrm{m}, 100 \AA$, Thermo Scientific, Waltham, WA). A spray voltage of $+2000 \mathrm{~V}$ was used with a heated ion transfer setting of 
$275^{\circ} \mathrm{C}$ for desolvation. The on-line reversed-phase separation was performed on an Easy nano-LC 1000 system using a flow rate of $300 \mathrm{nl} / \mathrm{min}$ and a linear binary gradient from 3\% solvent B for 60 min to $35 \%$ solvent B, then to $90 \%$ solvent B for 5 min and finally isocratic $90 \%$ solvent B for $5 \mathrm{~min}$. An MS scan (400-1200 m/z) was recorded in the Orbitrap mass analyzer set at a resolution of 70,000 at $200 \mathrm{~m} / \mathrm{z}, 1 \times 10^{6}$ automatic gain control (AGC) target and 100 ms maximum ion injection time. The MS was followed by data-dependent collision-induced dissociation MS/MS scans at a resolution of 15,000 on the 15 most intense multiply charged ions at $2 \times 10^{4}$ intensity threshold, $2 \mathrm{~m} / \mathrm{z}$ isolation width and dynamic exclusion enabled for 30 seconds.

Targeted mass spectrometry analyses using multiple reaction monitoring (MRM) were performed as previously described ${ }^{20}$. Processed sample aliquots were quantified using a TSQ Vantage triple quadrupole mass spectrometer (Thermo Scientific, Waltham MA) equipped with an Easy nano-LC system (Thermo Scientific, Waltham MA). The mass spectrometer was operated with both Q1 and Q3 settings at 0.7 Da resolution. A spray voltage of $+1700 \mathrm{~V}$ was used with a heated ion transfer setting of $270^{\circ} \mathrm{C}$ for desolvation. The monitored peptide sequence, transitions, and collision energies for MRM are provided in Table S1. Mobile phases used were solvent A ( $0.1 \%$ formic acid in water) and solvent B ( $0.1 \%$ formic acid in $100 \%$ acetonitrile). Separation was performed on $10 \mu \mathrm{m}$ tip, $75 \mu \mathrm{m} \times$ $15 \mathrm{~cm}$ capillary columns (PicoTip ${ }^{\mathrm{TM}}$ emitter; New Objective, Woburn, MA) packed with Reprosil-Pur C18-AQ resin ( $3 \mu \mathrm{m}$, Dr. Maich $\mathrm{GmbH})$. The on-line reversed-phase separation was performed using a flow rate of $300 \mathrm{nl} / \mathrm{min}$ and a linear binary gradient from $3 \%$ solvent B isocratic for $5 \mathrm{~min}$ then to $15 \%$ solvent B for $3 \mathrm{~min}$, then to $35 \%$ solvent B for $32 \mathrm{~min}$ and finally to $90 \%$ solvent B in 3 min followed by a wash for 3 min with $90 \%$ solvent B, and reconditioning to initial conditions in $10 \mathrm{~min}$. A standard mixture of tryptic peptides was run to check the system performance.

\section{Data search}

Identification was performed using the Homo sapiens taxonomy (20,200 sequences) setting of the Swiss-Prot database (SwissProt_2015_06) with Proteome Discoverer 2.0 (version 2.0.0.802, Thermo Scientific). The processing workflow consisted of the following nodes (and respective parameters): Spectrum Selector for spectra pre-processing (precursor mass range: 350-5000 Da; S/N Threshold: 1.5), Sequest-HT search engine (Protein Database: see above; Enzyme: Trypsin; Max. missed cleavage sites: 2; Peptide length range 6-144 amino acids; Precursor mass tolerance: 10 ppm; Fragment mass tolerance: 0.02 Da; Static modification: cysteine carbamidomethylation; Dynamic modification: methionine oxidation, and pyro-glutamate (N-terminal Glu to pyroglutamate), and Percolator for peptide validation (FDR $<1 \%$ based on peptide q-value). Results were filtered to keep only the Master protein with at least one unique peptide, and protein grouping was allowed according to the parsimony principle. Non-targeted quantification of MS1 precursor ions and MRM data were analyzed using the Skyline 2.0 software (MacCoss Lab Software, University of Washington). The MS1 precursor isotopic import filter was set to a count of three, (M, M +1 , and $M+2$ ) at a resolution power of 60,000 at $400 \mathrm{~m} / \mathrm{z}$. Skyline used the spectral library established on search results to select precursors using the following criteria: precursor charge state 2,3,4; retention time windows of 5 minutes of MS/MS IDs. The precursor peak 
areas $(M, M+1, M+2)$ of a peptide were to represent the amount of this peptide. A relative quantification approach rather than absolute values was used for MRM quantification. The peak area of MS2 fragment ions, within the expected retention time of the peak, ensured the identity of the peak as measured by synthetic peptides during optimization; MS2 fragment ions were summed for 3-5 transitions for each peptide for MRM experiments. Therefore we compared the protein distribution patterns across the specimens but not the absolute levels of different proteins.

\section{Data annotation}

Gene ontology (GO) analysis was performed to identify the cellular component, molecular function, and biological process associated with the identified proteins by a web-based browser, the PANTHER (Protein ANalysis THrough Evolutionary Relationships) classification system (www.pantherdb.org) ${ }^{27,28}$.

\section{Data analysis}

Decellularization experiments data were collected from seven independent biological replicates. Targeted quantification data were collected from three independent biological replicates for peak area and peak found ratio calculation. For non-targeted experiment, each group contained at least 5 independent cartilage sections. All the results were analyzed using GraphPad Prism 5.0 (Graphpad, San Diego, CA, USA). Group differences were assessed using one-way analysis of variance (ANOVA) and Student paired $t$ test. The MS1precursor ions and the transitions monitored in MRM assay was provided (Table S1). Data for the heatmap illustration were generated by hierarchical cluster analysis performed in the Cluster $3.0^{29}$ and visualized in JAVA Treeview ${ }^{30}$. All the graphs were prepared in Microsoft Excel, PowerPoint 2013 or GraphPad Prism 5. Multivariable analyses were constructed to evaluate for specific differences in protein abundance due to joint site, disease state, and depth of the cartilage matrix. The multivariable regression model was constructed with three independent factors (joint site, disease state, and depth of the cartilage) to evaluate their association with the continuous outcome response variable (protein abundance). The model evaluated the predicted response due to each specific factor after controlling for the other two factors. Statistical significance of each factor and the overall model was reported at the $95 \%$ confidence level $(\mathrm{p}<0.05)$. The multivariable analyses were performed using JMP® Pro 11.2 (SAS, Cary, NC).

\section{Quantification of clusterin by immunoassay}

A human specific enzyme-linked immunosorbent assay (ELISA) (R\&D Systems, Minneapolis, MN, USA) was used to quantify clusterin in cartilage extracts in accordance with the manufacturers' protocols.

\section{Results}

\section{A single freeze/thaw cycle efficiently separated chondrocytes from cartilage sections}

Figure 1A depicts the concept of eliminating chondrocytes from cartilage utilizing serial freeze/thaw cycles in hypotonic (deionized water) solution. The majority of double-stranded DNA, which represents the intracellular contents of chondrocytes, was released in the first 
cycle (Figure 1B). During serial freeze/thaw cycles, potential artifactual loss of soluble proteins was monitored by measuring the concentrations of total protein and glycosaminoglycans (GAGs) within the hypotonic solution (Figure 1C and D). Less than 3.5\% GAGs and very limited amounts of protein were lost from cartilage sections after the first freeze/thaw cycle. Retention of proteoglycans within the section, monitored by toluidine blue staining, suggested no apparent loss of proteoglycans as a result of one freeze/thaw cycle (Figure 1E). Hematoxylin staining after the first freeze/thaw cycle showed that the majority of chondrocytes were depleted in the first freeze/thaw cycle (Figure 1F). Taken together, these results suggest that one freeze/thaw cycle in hypotonic solution effectively depleted the majority of chondrocytes from a cartilage section with minimal effect on the ECM components. We subsequently applied this decellularization process to all our cartilage sections in this study.

\section{The effect of cartilage section decellularization on protein identification efficiency}

To evaluate the proteins released during the decellularization procedure, we collected the supernatant released upon cell lysis and the residual decellularized cartilage matrix; intact (whole non-lysed) cartilage sections, adjacent to the sections used for decellularization, were extracted with guanidine- $\mathrm{HCl}$. Sections were processed from the superficial, intermediate and deep layers of cartilage. Proteins within these supernatants and guanidine- $\mathrm{HCl}$ extracts were submitted for mass spectrometry analysis using the method described above.

Combining results from the supernatant and the matched residual decellularized cartilage matrix, a total of 457 proteins were identified; $12 \%$ fewer (403) proteins were identified from the adjacent cartilage section extracted as a whole with guanidine-HC; (Figure 2A). A total of 143 proteins were detected solely within the supernatant; 99 proteins were detected solely within the residual of the decellularized section. By Gene Ontology (GO) analysis, extracellular matrix GO IDs were identified in the decellularized sections, intact sections and supernatants with a frequency of 58.0\%, 52.8\% and 44.6\% (Figure 2B). Taken together, these results suggest that separation of the intracellular contents from the extracellular matrix can modestly increase the identification of unique proteins from both the ECM and chondrocytes. Thus, these results demonstrate the success of this decellularization method for providing a more holistic and efficient approach to differential proteomics of cartilage.

\section{Surfactant increased cartilage protein extraction efficiency}

Substantial amounts of cartilage residue remained after guanidine- $\mathrm{HCl}$ extraction. To further improve the extraction efficiency and analytical performance of the chromatography, we tested several modifications of this protocol and monitored the effects using MRM analysis. The workflow of the quantitative proteomic analyses is summarized in Figure 3A (method 1). Of the total 138 peptides we monitored, 100 peptides were detectable from the fraction treated with surfactant whereas the conventional guanidine-HCl method without surfactant only generated 92 detectable peptides ( $8 \%$ less) (Table S2). Comparing the peak areas of the peptides detected by both methods (see heatmap Figure 4A), surfactant supplementation yielded higher peak areas $(3.4 \pm 2.2$ fold, mean \pm stdev) for all 92 peptides. The average peak found ratio (a measure of quantified transitions over desired transitions) of all targeted peptides was also improved significantly by surfactant supplementation $(P<0.05)$. 


\section{Ultrafiltration removed interference from cartilage extraction}

High abundance anionic polysaccharide molecules from cartilage tissue significantly affect the chromatography as they can be trapped in the analytical column and possibly interact with basic peptides thereby affecting their retention. In order to achieve optimal analytical performance by mass spectrometry, it is necessary to reduce the amount of polysaccharide molecules, i.e. peptides modified with glycosaminoglycan chains. Ultrafiltration after trypsin digestion was tested to determine the effect on proteomic analysis (Figure 3A, method 2). Ultrafiltration improved the chromatographic performance (Figure 4B); this led to an increase in the identified peptide number ( $n=69$ to 100 identified peptides representing a $45 \%$ increase), the peak area ( $1.6 \pm 0.7$ fold, mean \pm stdev), and the peak found ratio $(P<0.001)$.

\section{Variation in extraction protocols enable identification of different constituents of the cartilage proteome}

In order to understand the composition of cartilage protein components, we developed an in situ digestion protocol (method 2) to directly release peptides from cartilage. On the same amount of decellularized cartilage tissue we compared results from in situ digestion with ultrafiltration to results from conventional guanidine- $\mathrm{HCl}$ extraction with surfactant (method 1). The proteins extracted by the two different methods were analyzed qualitatively by nanoLC-Orbitrap mass spectrometry analysis (Thermo Velos Pro). We also quantified selected proteins in the cartilage ECM by MRM. The peptides identified using the two extraction methods are summarized in Figure 5. Guanidine- $\mathrm{HCl}$ extraction resulted in detection of 1557 peptide-queries representing 175 proteins. About $17.7 \%$ of the detected peptides belonged to the collagen super family (mainly collagen types 2, 3, 6, and 1). In situ trypsin digestion of adjacent sections of cartilage tissue resulted in detection of 1849 peptide-queries, however, representing only 93 proteins; collagen related peptides constituted about $57.3 \%$ of the total identified peptide-queries. Fibronectin, aggrecan G1 domain, and COMP related peptides constituted $5.8 \%, 7.3 \%$, and $3.7 \%$, respectively of the total identified peptide-queries from guanidine- $\mathrm{HCl}$ extraction; whereas, the peptides related to these three proteins constituted $7.7 \%, 4.3 \%$ and $2.7 \%$, respectively of the total peptidequeries identified by in situ digestion. Other important but less abundant proteins, such as noncollagenous leucine-rich repeat protein family and the matrix metalloproteinase family, constituted $65.4 \%$ of the total identified peptides from guanidine- $\mathrm{HCl}$ extraction in contrast to $28.1 \%$ from the in situ digestion method (Table S3).

\section{Identifying the collagen associated proteome}

Besides qualitative proteomic analysis, we also performed a quantitative MRM assay to more precisely quantify the amount of specific proteins of interest extracted from decellularized cartilage sections by methods 1 and 2 (Figure 4A). Comparing the peak areas of the 135 peptide transitions, 58 peptides were more abundant within the guanidine- $\mathrm{HCl}$ extract, including for instance, aggrecan core protein, COMP, thrombospondin-1, mimecan, lumican, biglycan, and decorin (Table 1). Interestingly, 56 peptide transitions, including for instance, the collagen superfamily, tenascin, fibronectin, and perlecan, were more abundant within the extract generated by in situ digestion. These results indicated that the residue 
remaining after guanidine- $\mathrm{HCl}$ extraction contained not only collagen proteins but also other proteins. These proteins, although detectable within the guanidine- $\mathrm{HCl}$ extract, were even more abundant within the in situ digestion and were likely to represent the collagenassociated proteome. These results also suggested that the quantification based on the conventional guanidine- $\mathrm{HCl}$ method underestimated these collagen-associated proteins.

Of the proteins we quantified, cartilage intermediate layer protein (CILP) presented a distinct distribution pattern. Peptides derived from the CILP1 C1 subunit were enriched in guanidine- $\mathrm{HCl}$ extracts while the peptides derived from the CILP1 C2 subunit were enriched in the in situ digestion extracts (Figure 6A). Similarly, the CILP2 C2 subunit was enriched in the in situ digestion extracts (Figure 6B). Overall, from the in situ digestion extracts, we identified more distinct peptides from C2 subunits of CILP1 and CILP2 than C1 subunits (Figure 6C).

\section{Integrative discovery proteomic results}

The combination of modifications described above provided a comprehensive evaluation of the ECM of cartilage and allowed us to explore the collagen-associated proteome in addition to the guanidine extractable proteome and collagen residue (Figure 3A). Protein extraction by guanidine- $\mathrm{HCl}$ allowed a holistic approach for discovering proteins from cartilage tissue without being obscured by the dominant abundance of collagens. With tissue decellularization, surfactant and ultrafiltration, we identified a total of 425 proteins from all layers, joints, and different physiological conditions from guanidine- $\mathrm{HCl}$ extracts (Figure 3B, Table S4). Around 200 proteins were identified in each section. Although the superficial layer apparently yielded a higher number of identified proteins, this was not significantly different compared to other layers after correcting for decellurized section area (Figure 7A). However, more unique proteins were identified in the superficial layer than the other two layers. No significant differences in numbers of identified peptides were discerned by joint type (knee vs hip) or physiological condition (non-OA vs OA). The protein distribution in the different layers is depicted in Figure 7B. A total of 198 proteins (47\%) were common to all three layers (superficial, intermediate and deep) of cartilage tissue. A total of 257 proteins were shared between the superficial and intermediate layers (63\% of 406 proteins in total) whereas, 218 proteins were shared between the intermediate and deep layers (68\% of 320 proteins in total).

Comparing healthy non-OA to hip and knee OA cartilage (Figure 7C), $176(41 \%)$ of all the 425 identified proteins were identical between the three groups. Hip and knee OA samples shared 53\% identical proteins (182 proteins of total 341 proteins). These two OA samples had similar numbers of proteins identified in healthy cartilage, 58\% and 56\% respectively. By Gene Ontology (GO) analysis, the 425 identified proteins represented 6272 GO IDs (Figure S1). As expected, extracellular, intracellular and other subcellular proteins were identified. Of these, $51 \%$ of GO IDs indicated proteins associating with the extracellular matrix.

This approach also enabled us to evaluate the relative abundance of specific proteins and their peptide coverage by site and tissue depth. For example, clusterin was identified in all cartilage layers. Overall nineteen different peptides derived from clusterin were identified 
with a sequence coverage of $35.6 \%$. These peptides were distributed across the entire protein. Comparing the precursor ion intensity chromatogram from full scan mass spectral data (MS1) acquired during non-targeted discovery experiments, we found that clusterin was consistently enriched in the intermediate layer of healthy knee cartilage (Figure 8A, Table S5). To further characterize clusterin localization within the articular cartilage, protein from different layers was extracted by guanidine- $\mathrm{HCl}$ and the clusterin content was determined by ELISA (Figure 8B). Similar to the mass spectrometry analysis results, clusterin was enriched in the intermediate layer of the healthy knee cartilage.

\section{Cartilage composition varied by joint site, disease state and depth of the cartilage}

In order to explore the cartilage composition differences with respect to joint site, disease state and the depth of the cartilage tissue, we performed a multivariable regression analysis with all three factors simultaneously (Table 2). This method provides an indication of differences that are unique to one or more of the three factors and improves the precision of the estimate. In Table 2 we present the $p$ value generated from the Effect test that provides an indication of whether the factor is independently associated with the peptide after controlling for the other two factors and also the $p$ value of the model with all factors considered. Joint site differences included aggrecan core protein G1 and G2 domains (PGCA-G1 and G2), both significantly enriched in hip cartilage. Besides aggrecan, several other proteins were also enriched in hip cartilage, including hyaluronan and proteoglycan link protein 1 (HPLN1), matrilin-3 (MATN3), serine protease HTRA1 (HTRA1), chondroadherin (CHAD), clusterin (CLUS), SPARC-related modular calcium-binding protein 2 SMOC2), and carbonic anhydrase 1 (CAH1), all of which have been identified from our previous study in which three proteins, HPLN1, CHAD and SMOC2, were significantly enriched in hip versus knee cartilage a total of 2.5, 2.2, and 2.0 fold, respectively ${ }^{14}$. Possibly due to the increased sensitivity of the current methods, metalloproteinase inhibitor 3 (TIMP3) and emilin-1 (EMIL1), which were not identified in our previous study, were also enriched in hip cartilage. Unlike most of the other proteins, Chitinase-3-like protein 1 (CH3L1) and interstitial collagenase (MMP1) demonstrated significant enrichment in knee cartilage.

Aggrecan core protein was also significantly enriched in the deep layer of cartilage. Pericellular matrix localized protein, type VI collagen (CO6A1, CO6A2, and CO6A3), demonstrated a significant enrichment in the superficial layer and declined with depth. This is consistent with the observation that more chondrocytes are present in the superficial layer. Consistent with our previous study ${ }^{20}$, vitronectin (VTNC), proteoglycan 4 (PRG4), tenascin$\mathrm{C}$ (TENA) and tenascin-X (TENX) were enriched in the superficial layer. Type XII collagen, one of the Fibril Associated Collagens with Interrupted Triple helices (FACIT), mimecan (MIME) and serpin H1 (SERPH) were also significantly enriched in the superficial layer.

Unique to this study, we investigated disease state related differences of the cartilage proteome. Cartilage Oligomeric Matrix Protein (COMP) showed a disease-related significant decrease within the cartilage tissue. Complement C1q subunits (C1QA, C1QB, C1QC) were detectable in osteoarthritic cartilage but were all decreased. Annexin (ANXA1 and ANXA2), clusterin (CLUS) and versican core protein (CSPG2) were all decreased in 
osteoarthritic cartilage. On the other hand, procollagen C-endopeptidase enhancer 1(PCOC1), gelsolin (GELS), and EGF-like repeat and discoidin I-like domain-containing protein 3 (EDIL3) within osteoarthritic cartilage were all significantly increased.

\section{Discussion}

We have developed a method of extracting and analyzing minute quantities (1-2 mg) of cartilage to identify and quantify the cartilage ECM proteins of decellularized tissue. Through this study we learned that variations in the extraction methodology lead to the identification of different constituents of the cartilage proteome. We tested the utility of deionized water to lyse chondrocytes based on their known sensitivity to hypo-osmotic pressure. Through careful serial monitoring of the dsDNA, GAGs and total protein content of cartilage sections, we demonstrated that we avoided loss of the ECM but still achieved decellularization. The quantitative experiment results suggested that that surfactant was compatible with the guanidine- $\mathrm{HCl}$ extraction buffer and could improve the extraction efficiency. In contrast to other studies ${ }^{31-35}$, we avoided sample heating to prevent artificial protein modification and activation of endogenous enzyme activity within cartilage tissue. Our previous study investigated the cartilage extraction residue by trypsin digestion ${ }^{14}$ and lead to the identification of the proteins retained after $\mathrm{GuHCl}$ extraction. In the present study, we optimized the workflow and incorporated other modifications, such as including surfactant and combining washed solution and extraction, to generate a comprehensive method for differential proteomics of cartilage. From the present study, we also found that results from conventional guanidine- $\mathrm{HCl}$ extraction complemented those from in situ trypsin digestion; the two methods together provided a more holistic characterization of the cartilage. In situ trypsin digestion yielded almost $20 \%$ more peptides with the increase accounted for by the collagen superfamily. Although this method may not allow full characterization of the collagen associated minor protein components, it nevertheless provided some intriguing insights into these components that hitherto were not possible with guanidine- $\mathrm{HCl}$ extraction alone.

Decellularization has been performed on a variety of tissues, including cardiac, vascular, and pulmonary tissue $15,24,25,36$. Most of these studies were focused on tissue engineering applications with the goal of recapitulating a tissue scaffold with the appropriate native constituents, compressive properties and durability. Microscopy in one decellularization study suggested that the meshwork structure was maintained, however, only $25 \%$ of GAGs and $70 \%$ of collagen were retained ${ }^{37}$. Another study, focused on developing a decellularized replacement for facet joint cartilage, completely decellularized cartilage based on a histological assessment, using $2 \%$ SDS for 8 hours; this protocol also resulted in significant depletion of the GAG content ${ }^{15}$. We aimed to minimize or prevent the loss of ECM components for our proteomic analyses. We therefore ruled out use of SDS, commonly used to solubilize cytoplasmic and nuclear membranes, as it removed GAGs and damaged collagens $^{23}, 24$. We also considered the sequential extraction method of Wilson et al. using sodium chloride $(\mathrm{NaCl})$ and guanidine- $\mathrm{HCl}^{11,38,39}$ to process whole mouse cartilage. However, $\mathrm{NaCl}$ also extracts extracellular matrix proteins. In a proteomic study on aorta tissue, $\mathrm{NaCl}$ was shown to extract loosely bound ECM protein and degraded protein 
products $^{24}$. As shown here, hypotonic solution with snap freezing minimized these confounds and proved suitably reliable for preserving cartilage extracellular matrix.

The combination of the conventional guanidine- $\mathrm{HCl}$ extraction and in situ trypsin digestion provided some insights into the collagen-associated proteome. Of particular interest was the fact that within a protein, different domains could be extracted by one versus another extraction method. This suggested that one part of the molecule might be bound to collagen and provided therefore a method of mapping the interactions (molecular architecture) of proteins within cartilage. An example of this was provided by the cartilage intermediate layer proteins 1 and 2 (CILP1 and CILP2), basic non-collagenous proteins synthesized by articular chondrocytes. Immunohistochemical analysis suggests that CILP1 is generated by chondrocytes and deposited in the interterritorial region of the intermediate layer of cartilage ${ }^{17}$. The CILP2 isoform shares $50.6 \%$ identity with CILP1 and appears to be localized in the deep intermediate layer ${ }^{40,41}$. CILP1 and CILP2 have central furin endoprotease consensus cleavage sites predicted to cause release of two chains ${ }^{17,40}$. Recent proteomic evaluation showed that CILP1-1 was enriched in the deep layer while CILP1-2 was deposited in the intermediate layer. Both variants of CILP2 were distributed similarly in the intermediate layer ${ }^{20}$. These data reveal that the two variants of CILP have distinctly different distributions within the cartilage ECM and imply that CILP1-2 and CILP2-2 crosslink with the collagen framework while CILP1-1 and CILP2-1 have less or no cross-linking to collagen. This example illustrates how differential extraction efficiency by these two methods can yield new insights into the localization of ECM proteins within cartilage tissue; namely, guanidine- $\mathrm{HCl}$ extraction can provide information on the highly soluble proteome whereas in situ digestion can provide additional information on the collagen framework including collagen-associated proteins.

Proteomic analysis can more reliably indicate the localization of a cartilage matrix protein compared to other methods, such as immunohistochemistry (IHC), the veracity of which can be reduced by low affinity antibodies and possibly also by limited access of antibodies to the corresponding epitope within cartilage. An example was provided by the clusterin protein. In contrast to results based on IHC that reported enrichment of clusterin within the superficial layers of healthy knee cartilage ${ }^{42,43}$, our proteomic and immunoassay methods of analyses revealed enrichment of clusterin in the intermediate and deep layers of the healthy knee cartilage. Prior results based on IHC analysis may have been confounded by the poor penetration of antibodies through the tight collagen framework in the intermediate and deep layers and by the presence of glycosaminoglycan in the ECM. Previous studies have suggested that the interplay of multiple assay parameters determines the effectiveness of a given protocol. The combination of different pretreatments for antigen retrieval, such glycosaminoglycan removal, and protease digestion, are generally required to obtain robust results ${ }^{44-47}$. Each antibody requires a specific combination of chemical pretreatments that must be empirically determined to achieve optimal staining levels. Mass spectrometry analysis involves extraction and processing of matrix proteins for detection of peptides derived from the matrix proteins. This approach overcomes the impenetrability of the cartilage matrix and provides a more robust result. However, this approach requires a great deal of effort to separate the proteins by specific locations, such as depth, and requires analysis of multiple samples to accomplish the localization. In our study, peptides derived 
from two domains of clusterin were identified across different cartilage layers by an MS approach with a protein coverage rate of up to $35.6 \%$; five peptides identified across all layers behaved similarly, i.e. were enriched in the intermediate layer of cartilage. Our result demonstrates the advantages of combining HPLC and mass spectrometry for studying protein distribution. These mass spectrometry based results likely more closely reflect the actual protein abundance and localization pattern of clusterin within cartilage ECM based on their agreement with another study that evaluated clusterin mRNA expression that also revealed higher level expression in the intermediate layer of cartilage ${ }^{48}$.

Investigations into biomarkers of OA have been underway for more than 20 years and have led to many discoveries ${ }^{49}$. The well-known biomarker of OA, COMP, which is increased in serum and synovial fluid after joint injury and in early osteoarthritis ${ }^{50,51}$, was significantly decreased within the osteoarthritic cartilage tissue. Calcium-regulated protein, gelsolin, was decreased in the plasma of RA patients ${ }^{52}$. However, it was reported as increased in the OA synovial fluid sample ${ }^{53}$. In the present study, we found that gelsolin was increased in the OA cartilage. Furthermore, it was enriched in the superficial layer of the healthy and OA cartilage. Procollagen C-endopeptidase enhancer 1 (PCOC1) involves in the bone mechanical properties ${ }^{54}$ and also controls the rate and the amount of deposition of collagen fiber ${ }^{55}$. Previous study reported the PCOC1 gene was increased in the synovium of the OA patients. The previous published study demonstrated by transgenic mice showed the EDIL3 mutation disturbed the assembly of the cartilage collagen framework and increased the incidence and severity of $\mathrm{OA}$ with age ${ }^{56}$. Previous study of investigating different cartilage tissue compositions revealed variant protein expression patterns between these cartilages, which may relate to tissue mechanical properties and joint disease pathology ${ }^{14}$. In the present study, we have compared the difference between the knee and hip cartilage with the optimized method with decellularization procedure and other modifications to generate more comprehensive results. Besides the proteins identified from the previous study, we also identified TIMP3, CAH1 and EMIL1 as hip cartilage enriched proteins; CH3L1 and MMP1 as knee cartilage enriched proteins. These joint-related proteins could serve as the biomarkers to distinguish the disease pathology change related to the particular joint.

Zonal distribution of the matrix proteins can serve as an indicator of disease stage and progression status since cartilage degeneration starts at the articular surface ${ }^{57}$. In the present study, we found that the superficial layer had more unique proteins identified and more proteins in high abundance. Only a few proteins, including aggrecan core protein, fibroblast growth factor-binding protein 2 (FGFP2), and phospholipase A2 (PA2GA), were enriched in the deep layer of cartilage. The identification of the type VI collagen (COL6A1, COL6A2, and COL6A3) enriched in the superficial layer indicates the preservation of the pericellular matrix 8,22 after the decellularization procedure. The heterogeneous distribution of cartilage proteins by site, depth and disease state indicates a rich area for further research for elucidating the functional properties of cartilage.

\section{Conclusion}

In summary, our results demonstrate that cartilage could be decellularized with minimal loss of ECM components to obtain specific data on the matrix proteome without the confounding 
by intracellular proteins. Surfactant could be utilized together with guanidine-HCl to improve cartilage extraction efficiency. Ultrafiltration was successfully adapted for eliminating larger polysaccharide molecules from cartilage extracts and improved the analytic performance of the proteomic evaluation. Guanidine- $\mathrm{HCl}$ extraction was suitable for analysis of soluble matrix proteins. However, in situ digestion with trypsin provided the ability to evaluate collagen and the collagen-associated proteome. Together, these two methods can be utilized to gain holistic insights into the distribution of proteins within cartilage. With the modified methodology, we could more holistically investigate the characteristics of cartilage. Moreover, the results led to the identification of potential biomarkers of OA. For instance, matrix proteins changing in their zonal distribution may be used to categorize the disease stage. Joint specific biomarkers, which distinguished OA from non-OA may have utility as diagnostics. Finally, proteins with joint site and disease pathology related change were also identified in the present study; these could be particularly valuable for identifying joint-site specific pathology through body fluid analyses.

\section{Supplementary Material}

Refer to Web version on PubMed Central for supplementary material.

\section{Acknowledgments}

Role of funding sources

This study was supported by OARSI Collaborative Scholarship to M-FH, Collaborative Exchange Award from the Orthopaedic Research Society to VBK; and NIH/NIA P30-AG-028716. Mass spectrometers were funded by the Crafoord Foundation and Inga-Britt and Arne Lundberg Foundation and other financial support was obtained from the Swedish Research Council (2010-2889) to PÖ.

\section{References}

1. Mow VC, Ratcliffe A, Poole AR. Cartilage and diarthrodial joints as paradigms for hierarchical materials and structures. Biomaterials. 1992; 13(2):67-97. [PubMed: 1550898]

2. Heinegård D. Proteoglycans and more-from molecules to biology. Int J Exp Pathol. 2009; 90(6): 575-86. [PubMed: 19958398]

3. Schaefer L, Schaefer RM. Proteoglycans: from structural compounds to signaling molecules. Cell Tissue Res. 2010; 339(1):237-46. [PubMed: 19513755]

4. Mendler M, Eich-Bender SG, Vaughan L, Winterhalter KH, Bruckner P. Cartilage contains mixed fibrils of collagen types II, IX, and XI. J Cell Biol. 1989; 108(1):191-7. [PubMed: 2463256]

5. Wu JJ, Woods PE, Eyre DR. Identification of cross-linking sites in bovine cartilage type IX collagen reveals an antiparallel type II-type IX molecular relationship and type IX to type IX bonding. J Biol Chem. 1992; 267(32):23007-14. [PubMed: 1429648]

6. Buckwalter JA, Mankin HJ. Articular cartilage: tissue design and chondrocyte-matrix interactions. Instr Course Lect. 1998; 47:477-86. [PubMed: 9571449]

7. Eyre DR. Collagens and cartilage matrix homeostasis. Clin Orthop Relat Res. 2004; (427 Suppl):S118-22. [PubMed: 15480053]

8. Guilak F, Alexopoulos LG, Upton ML, Youn I, Choi JB, Cao L, Setton LA, Haider MA. The pericellular matrix as a transducer of biomechanical and biochemical signals in articular cartilage. Ann N Y Acad Sci. 2006; 1068:498-512. [PubMed: 16831947] 
9. Poole CA, Matsuoka A, Schofield JR. Chondrons from articular cartilage. III. Morphologic changes in the cellular microenvironment of chondrons isolated from osteoarthritic cartilage. Arthritis Rheum. 1991; 34(1):22-35. [PubMed: 1984777]

10. Buckwalter JA, Mankin HJ, Grodzinsky AJ. Articular cartilage and osteoarthritis. Instr Course Lect. 2005; 54:465-80. [PubMed: 15952258]

11. Wilson R, Norris EL, Brachvogel B, Angelucci C, Zivkovic S, Gordon L, Bernardo BC, Stermann J, Sekiguchi K, Gorman JJ, Bateman JF. Changes in the chondrocyte and extracellular matrix proteome during post-natal mouse cartilage development. Mol Cell Proteomics. 2012; 11(1):M111014159.

12. Guo D, Tan W, Wang F, Lv Z, Hu J, Lv T, Chen Q, Gu X, Wan B, Zhang Z. Proteomic analysis of human articular cartilage: identification of differentially expressed proteins in knee osteoarthritis. Joint Bone Spine. 2008; 75(4):439-44. [PubMed: 18468937]

13. Wu J, Liu W, Bemis A, Wang E, Qiu Y, Morris EA, Flannery CR, Yang Z. Comparative proteomic characterization of articular cartilage tissue from normal donors and patients with osteoarthritis. Arthritis Rheum. 2007; 56(11):3675-84. [PubMed: 17968891]

14. Önnerfjord P, Khabut A, Reinholt FP, Svensson O, Heinegard D. Quantitative proteomic analysis of eight cartilaginous tissues reveals characteristic differences as well as similarities between subgroups. J Biol Chem. 2012; 287(23):18913-24. [PubMed: 22493511]

15. Elder BD, Kim DH, Athanasiou KA. Developing an articular cartilage decellularization process toward facet joint cartilage replacement. Neurosurgery. 2010; 66(4):722-7. discussion 727. [PubMed: 20305493]

16. Hoemann CD, Sun J, Chrzanowski V, Buschmann MD. A multivalent assay to detect glycosaminoglycan, protein, collagen, RNA, and DNA content in milligram samples of cartilage or hydrogel-based repair cartilage. Anal Biochem. 2002; 300(1):1-10. [PubMed: 11743684]

17. Lorenzo P, Bayliss MT, Heinegard D. A novel cartilage protein (CILP) present in the mid-zone of human articular cartilage increases with age. J Biol Chem. 1998; 273(36):23463-8. [PubMed: 9722583]

18. DiCesare PE, Morgelin M, Carlson CS, Pasumarti S, Paulsson M. Cartilage oligomeric matrix protein: isolation and characterization from human articular cartilage. J Orthop Res. 1995; 13(3): 422-8. [PubMed: 7602403]

19. Pfister BE, Aydelotte MB, Burkhart W, Kuettner KE, Schmid TM. Del1: a new protein in the superficial layer of articular cartilage. Biochem Biophys Res Commun. 2001; 286(2):268-73 [PubMed: 11500032]

20. Müller C, Khabut A, Dudhia J, Reinholt FP, Aspberg A, Heinegard D, Onnerfjord P. Quantitative proteomics at different depths in human articular cartilage reveals unique patterns of protein distribution. Matrix Biol. 2014:34-45. [PubMed: 25193283]

21. Cillero-Pastor B, Eijkel GB, Kiss A, Blanco FJ, Heeren RM. Matrix-assisted laser desorption ionization-imaging mass spectrometry: a new methodology to study human osteoarthritic cartilage. Arthritis Rheum. 2013; 65(3):710-20. [PubMed: 23280504]

22. Zhang Z, Jin W, Beckett J, Otto T, Moed B. A proteomic approach for identification and localization of the pericellular components of chondrocytes. Histochem Cell Biol. 2011; 136(2): 153-62. [PubMed: 21698479]

23. Angel PM, Nusinow D, Brown CB, Violette K, Barnett JV, Zhang B, Baldwin HS, Caprioli RM. Networked-based characterization of extracellular matrix proteins from adult mouse pulmonary and aortic valves. J Proteome Res. 2011; 10(2):812-23. [PubMed: 21133377]

24. Didangelos A, Yin X, Mandal K, Baumert M, Jahangiri M, Mayr M. Proteomics characterization of extracellular space components in the human aorta. Mol Cell Proteomics. 2010; 9(9):2048-62. [PubMed: 20551380]

25. Gilbert TW, Sellaro TL, Badylak SF. Decellularization of tissues and organs. Biomaterials. 2006; 27(19):3675-83. [PubMed: 16519932]

26. Chandrasekhar S, Esterman MA, Hoffman HA. Microdetermination of proteoglycans and glycosaminoglycans in the presence of guanidine hydrochloride. Anal Biochem. 1987; 161(1): 103-8. [PubMed: 3578776] 
27. Mi H, Dong Q, Muruganujan A, Gaudet P, Lewis S, Thomas PD. PANTHER version 7: improved phylogenetic trees, orthologs and collaboration with the Gene Ontology Consortium. Nucleic Acids Res. 2010; 38:D204-10. Database issue. [PubMed: 20015972]

28. Thomas PD, Campbell MJ, Kejariwal A, Mi H, Karlak B, Daverman R, Diemer K, Muruganujan A, Narechania A. PANTHER: a library of protein families and subfamilies indexed by function. Genome Res. 2003; 13(9):2129-41. [PubMed: 12952881]

29. de Hoon MJ, Imoto S, Nolan J, Miyano S. Open source clustering software. Bioinformatics. 2004; 20(9):1453-4. [PubMed: 14871861]

30. Saldanha AJ. Java Treeview-extensible visualization of microarray data. Bioinformatics. 2004; 20(17):3246-8. [PubMed: 15180930]

31. Hansen KC, Kiemele L, Maller O, O’Brien J, Shankar A, Fornetti J, Schedin P. An in-solution ultrasonication-assisted digestion method for improved extracellular matrix proteome coverage. Mol Cell Proteomics. 2009; 8(7):1648-57. [PubMed: 19351662]

32. Nirmalan NJ, Hughes C, Peng J, McKenna T, Langridge J, Cairns DA, Harnden P, Selby PJ, Banks RE. Initial development and validation of a novel extraction method for quantitative mining of the formalin-fixed, paraffin-embedded tissue proteome for biomarker investigations. J Proteome Res. 2011; 10(2):896-906. [PubMed: 21117664]

33. Liu NQ, Braakman RB, Stingl C, Luider TM, Martens JW, Foekens JA, Umar A. Proteomics pipeline for biomarker discovery of laser capture microdissected breast cancer tissue. J Mammary Gland Biol Neoplasia. 2012; 17(2):155-64. [PubMed: 22644111]

34. Braakman RB, Tilanus-Linthorst MM, Liu NQ, Stingl C, Dekker LJ, Luider TM, Martens JW, Foekens JA, Umar A. Optimized nLC-MS workflow for laser capture microdissected breast cancer tissue. J Proteomics. 2012; 75(10):2844-54. [PubMed: 22296676]

35. Little D, Thompson JW, Dubois LG, Ruch DS, Moseley MA, Guilak F. Proteomic differences between male and female anterior cruciate ligament and patellar tendon. PLoS One. 2014; 9(5):e96526. [PubMed: 24818782]

36. Welham NV, Chang Z, Smith LM, Frey BL. Proteomic analysis of a decellularized human vocal fold mucosa scaffold using 2D electrophoresis and high-resolution mass spectrometry. Biomaterials. 2013; 34(3):669-76. [PubMed: 23102991]

37. Pati F, Jang J, Ha DH, Won Kim S, Rhie JW, Shim JH, Kim DH, Cho DW. Printing threedimensional tissue analogues with decellularized extracellular matrix bioink. Nat Commun. 2014; 5:3935. [PubMed: 24887553]

38. Wilson R, Bateman JF. A robust method for proteomic characterization of mouse cartilage using solubility-based sequential fractionation and two-dimensional gel electrophoresis. Matrix Biol. 2008; 27(8):709-12. [PubMed: 18762257]

39. Wilson R, Belluoccio D, Bateman JF. Proteomic analysis of cartilage proteins. Methods. 2008; 45(1):22-31. [PubMed: 18442702]

40. Bernardo BC, Belluoccio D, Rowley L, Little CB, Hansen U, Bateman JF. Cartilage intermediate layer protein 2 (CILP-2) is expressed in articular and meniscal cartilage and down-regulated in experimental osteoarthritis. J Biol Chem. 2011; 286(43):37758-67. [PubMed: 21880736]

41. Johnson K, Farley D, Hu SI, Terkeltaub R. One of two chondrocyte-expressed isoforms of cartilage intermediate-layer protein functions as an insulin-like growth factor 1 antagonist. Arthritis Rheum. 2003; 48(5):1302-14. [PubMed: 12746903]

42. Malda J, ten Hoope W, Schuurman W, van Osch GJ, van Weeren PR, Dhert WJ. Localization of the potential zonal marker clusterin in native cartilage and in tissue-engineered constructs. Tissue Eng Part A. 2010; 16(3):897-904. [PubMed: 19814590]

43. McCarthy HS, Malda J, Richardson JB, Roberts S. Increased Production of Clusterin in Biopsies of Repair Tissue following Autologous Chondrocyte Implantation. Cartilage. 2013

44. Ahrens MJ, Dudley AT. Chemical Pretreatment of Growth Plate Cartilage Increases Immunofluorescence Sensitivity. Journal of Histochemistry and Cytochemistry. 2011; 59(4):408418. [PubMed: 21411811]

45. Naumann A, Dennis JE, Awadallah A, Carrino DA, Mansour JM, Kastenbauer E, Caplan AI. Immunochemical and mechanical characterization of cartilage subtypes in rabbit. J Histochem Cytochem. 2002; 50(8):1049-58. [PubMed: 12133908] 
46. Werkmeister JA, Ramshaw JA. Monoclonal antibodies to type V collagen for immunohistological examination of new tissue deposition associated with biomaterial implants. J Histochem Cytochem. 1991; 39(9):1215-20. [PubMed: 1918939]

47. Vilamitjana J, Barge A, Julliard AK, Herbage D, Baltz T, Garrone R, Harmand MF. Problems in the immunolocalization of type IX collagen in fetal calf cartilage using a monoclonal antibody. Connect Tissue Res. 1989; 18(4):277-92. [PubMed: 2472927]

48. Connor JR, Kumar S, Sathe G, Mooney J, O'Brien SP, Mui P, Murdock PR, Gowen M, Lark MW. Clusterin expression in adult human normal and osteoarthritic articular cartilage. Osteoarthritis Cartilage. 2001; 9(8):727-37. [PubMed: 11795992]

49. Hsueh MF, Onnerfjord P, Kraus VB. Biomarkers and proteomic analysis of osteoarthritis. Matrix Biol. 2014; 39C:56-66. [PubMed: 25179675]

50. Lohmander LS, Saxne T, Heinegard DK. Release of cartilage oligomeric matrix protein (COMP) into joint fluid after knee injury and in osteoarthritis. Ann Rheum Dis. 1994; 53(1):8-13. [PubMed: 8311563]

51. Hedbom E, Antonsson P, Hjerpe A, Aeschlimann D, Paulsson M, Rosa-Pimentel E, Sommarin Y, Wendel M, Oldberg A, Heinegard D. Cartilage matrix proteins. An acidic oligomeric protein (COMP) detected only in cartilage. J Biol Chem. 1992; 267(9):6132-6. [PubMed: 1556121]

52. Osborn TM, Verdrengh M, Stossel TP, Tarkowski A, Bokarewa M. Decreased levels of the gelsolin plasma isoform in patients with rheumatoid arthritis. Arthritis Research \& Therapy. 2008; 10(5):R117-R117. [PubMed: 18822171]

53. Mateos J, Lourido L, Fernandez-Puente P, Calamia V, Fernandez-Lopez C, Oreiro N, Ruiz-Romero C, Blanco FJ. Differential protein profiling of synovial fluid from rheumatoid arthritis and osteoarthritis patients using LC-MALDI TOF/TOF. J Proteomics. 2012; 75(10):2869-78. [PubMed: 22245418]

54. Steiglitz BM, Kreider JM, Frankenburg EP, Pappano WN, Hoffman GG, Meganck JA, Liang X, Hook M, Birk DE, Goldstein SA, Greenspan DS. Procollagen C proteinase enhancer 1 genes are important determinants of the mechanical properties and geometry of bone and the ultrastructure of connective tissues. Mol Cell Biol. 2006; 26(1):238-49. [PubMed: 16354695]

55. Moali C, Font B, Ruggiero F, Eichenberger D, Rousselle P, Francois V, Oldberg A, BrucknerTuderman L, Hulmes DJ. Substrate-specific modulation of a multisubstrate proteinase. C-terminal processing of fibrillar procollagens is the only BMP-1-dependent activity to be enhanced by PCPE-1. J Biol Chem. 2005; 280(25):24188-94. [PubMed: 15834133]

56. Helminen HJ, Saamanen AM, Salminen H, Hyttinen MM. Transgenic mouse models for studying the role of cartilage macromolecules in osteoarthritis. Rheumatology (Oxford). 2002; 41(8):84856. [PubMed: 12154201]

57. Hollander AP, Pidoux I, Reiner A, Rorabeck C, Bourne R, Poole AR. Damage to type II collagen in aging and osteoarthritis starts at the articular surface, originates around chondrocytes, and extends into the cartilage with progressive degeneration. J Clin Invest. 1995; 96(6):2859-69. [PubMed: 8675657] 
A)
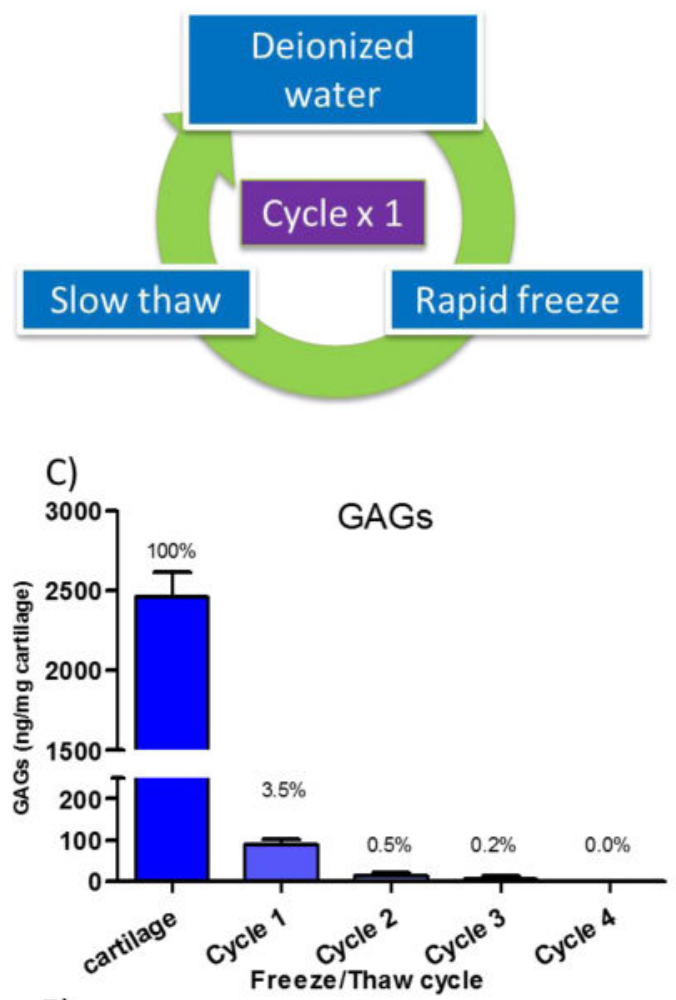

E)

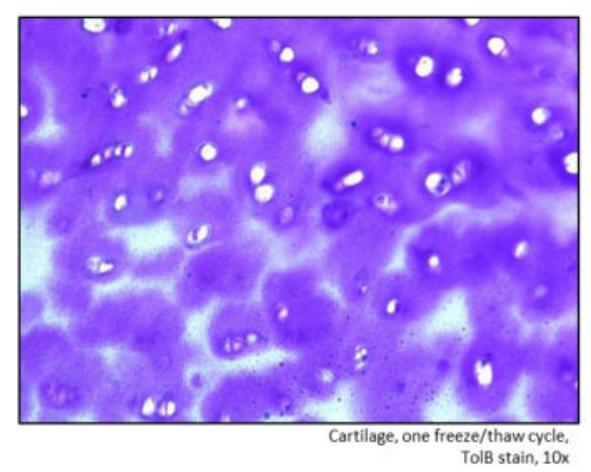

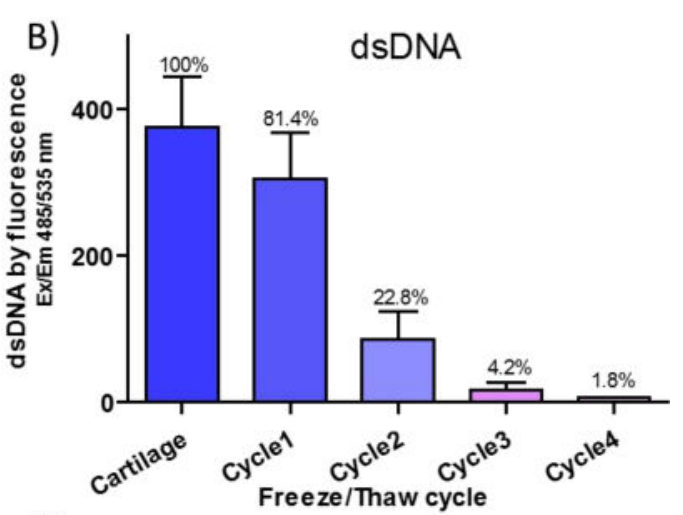

D)

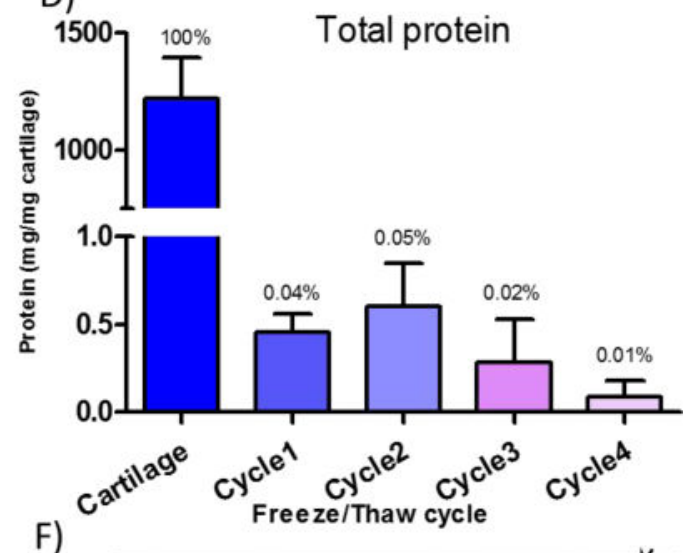

F)

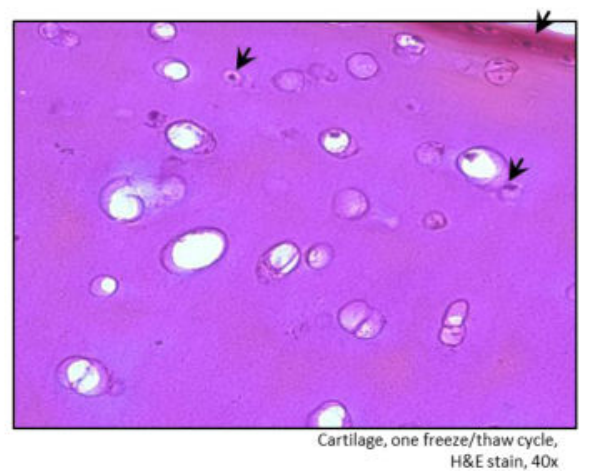

Figure 1.

One freeze/thaw cycle is sufficient for removing chondrocytes without negatively impacting the cartilage extracellular matrix. A) Schematic representation showing the decellularization protocol. A $12 \mu \mathrm{m}$ thick frozen tissue section was immersed in hypotonic solution (deionized $\mathrm{H}_{2} \mathrm{O}$ ) and subsequently underwent rapid freeze/slow thaw cycles (between $-20^{\circ} \mathrm{C}$ and $25^{\circ} \mathrm{C}$ ). The supernatant was collected in order to monitor the material released from the section due to each freeze/thaw cycle. B-D) Double stranded DNA (dsDNA), glycosaminoglycans (GAGs) and total protein within the supernatant were quantified to determine the efficiency and effect of the decellularization protocol. The majority of dsDNA, indicative of the cellular component of cartilage, was released after one freeze/thaw cycle. Only $3.5 \%$ of total GAG was released after one freeze/thaw cycle. Taken together, these results suggested that one freeze/thaw cycle was sufficient to separate cartilage cellular components from the ECM without significant loss of the loosely linked GAGs. Compared 
to the total section, the protein lost during this protocol was only $0.04 \%$. E) Toluidine blue stained tissue section after one freeze/thaw cycle indicating by the degree of blue stain that the majority of GAGs was retained. F) A haematoxylin-eosin (HE) stained and decelluarized section demonstrating that most chondrocytes were eliminated from the tissue section by hypotonic solution. Together panels $\mathrm{E}$ and $\mathrm{F}$ demonstrate the efficiency and matrix preserving characteristics of our decellularization protocol. 
A)

Supernatant

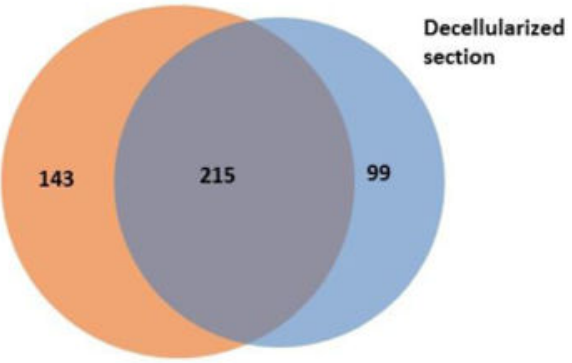

B)

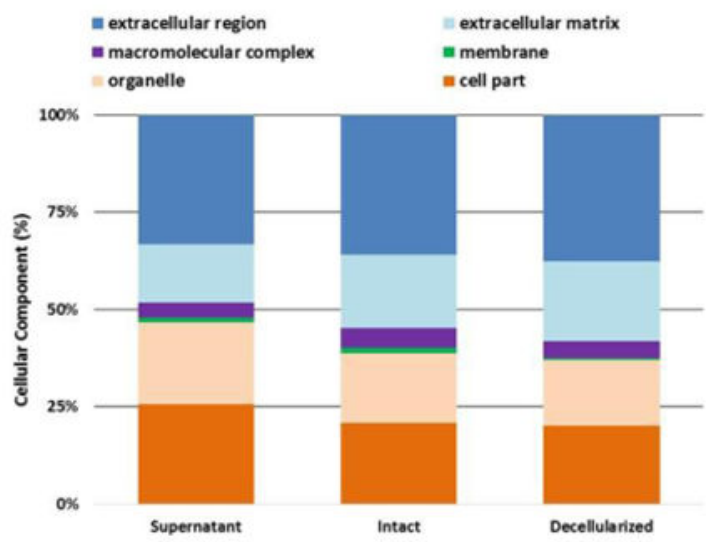

Figure 2.

Mass spectrometry analysis of the protein contents from supernatants and, the matched residual decellularized cartilage section, compared with guanidine- $\mathrm{HCl}$ extracted adjacent intact cartilage sections. Gene ontology annotation was used to classify the proteins identified from each type of sample. A) Gene ontology annotation results suggested that decellularized sections contained the most GO IDs associated with extracellular matrix while the supernatants contained the least. B) A total of 457 proteins were identified from combined supernatant and the matched residual decellularized section. Of these, 143 proteins were solely detected from the supernatants and 99 proteins were solely detected from the residual decellularized sections. 
A)

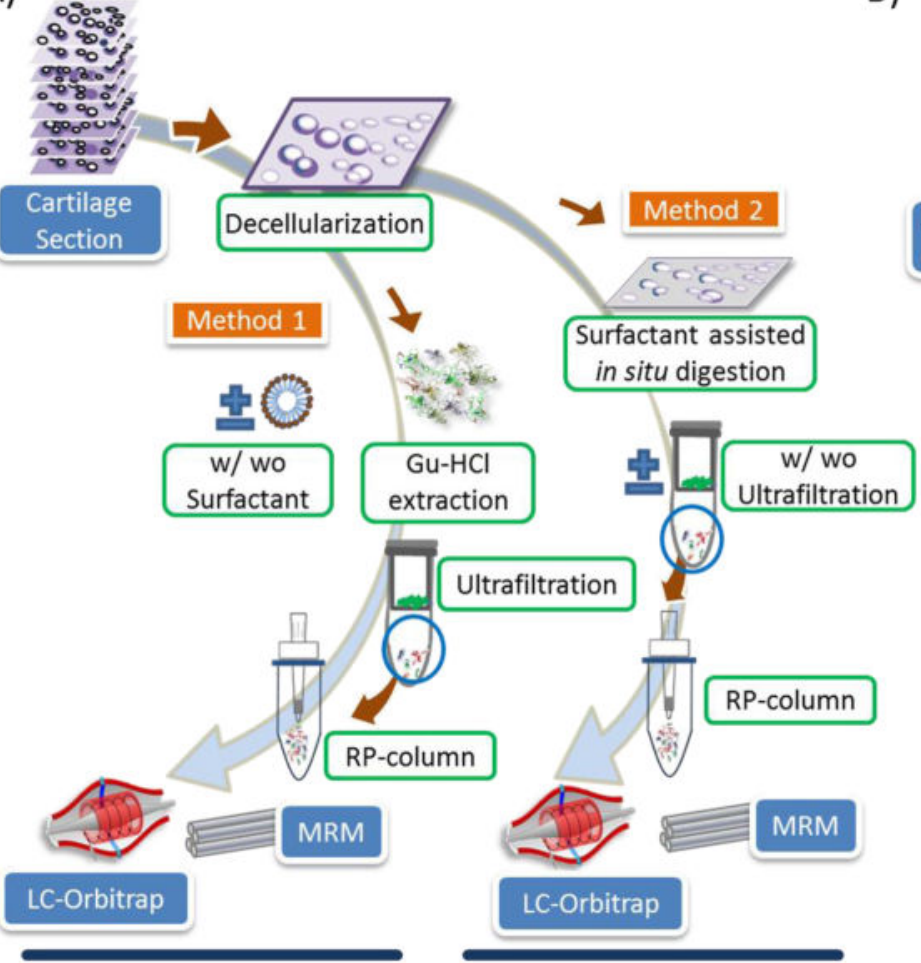

B)

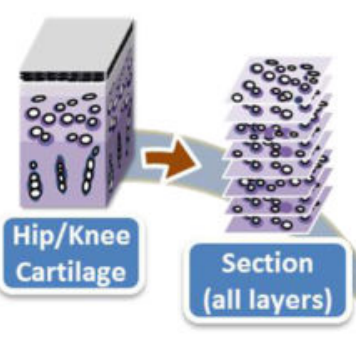

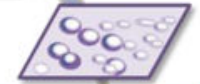

Decellularization
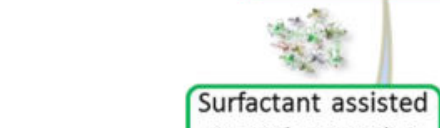
$\mathrm{Gu}-\mathrm{HCl}$ extraction

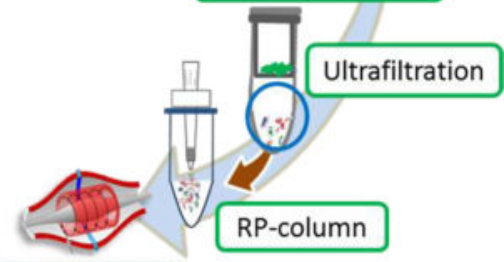

LC-Orbitrap

\section{Proteomic Data Analysis}

Figure 3.

Workflow of cartilage tissue proteomic analysis. A) Cartilage sections were generated for methodology development. Chondrocytes were removed by a single freeze/thaw cycle in hypotonic solution. Cartilage proteins were extracted by guanidine- $\mathrm{HCl}$ extraction buffer with/without surfactant (method 1). Extracts were treated by ultrafiltration to remove interfering GAGs and the residual salt was removed by reverse-phase (RP) spin column. Adjacent decellularized sections were extracted by the in situ trypsin digestion method with surfactant (method 2). Extracted peptides were treated with/without ultrafiltration. For each of these methods, proteomic analysis was performed by LC-Orbitrap MS (qualitative proteomics) and LC-triple quadrupole MS (quantitative MRM proteomics). B) Method 3 represents surfactant assisted guanidine- $\mathrm{HCl}$ extraction (with ultrafiltration) of cartilage sections from all layers (superficial, intermediate and deep), different joints (knees and hips), and different physiological conditions (healthy and OA) allowing a holistic discovery experiment by Orbitrap analysis of the soluble cartilage protein components. 
A)

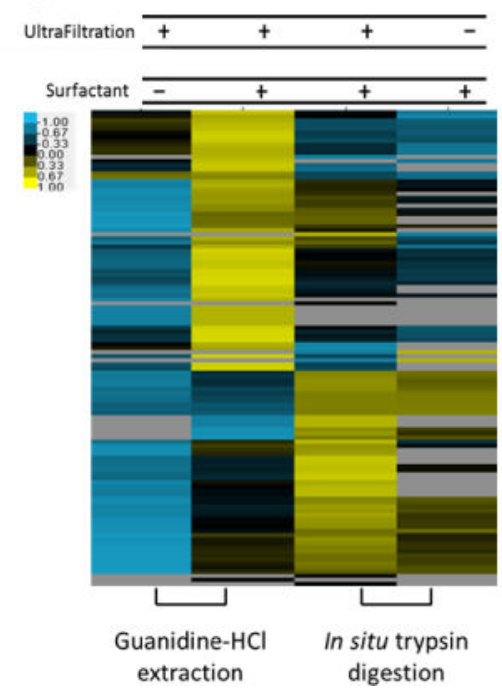

B)

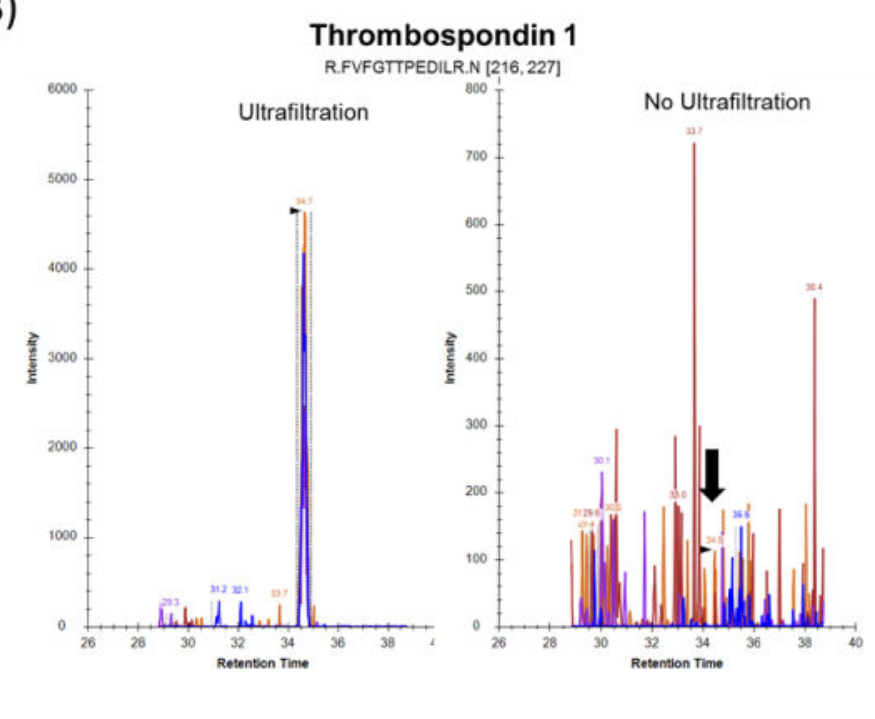

Figure 4.

Quantitative mass spectrometry by Multiple Reaction Monitoring (MRM) to assess the affects of surfactant, ultrafiltration, and different extraction methods on proteomic analyses. A) Adjacent sections of cartilage were extracted by methods 1 and 2 (described in Figure 2). By MRM we monitored 135 peptides representing 38 proteins. Each row represents an identified peptide; the color of a band in a column ranges from blue $(-1)$ representing an amount below the mean obtained by the 4 extraction methods, black (0) representing values equal to the mean and yellow $(+1)$ representing amounts above the mean. Adding surfactant to the guanidine- $\mathrm{HCl}$ extraction buffer improved the signal intensities an average 3 fold based on peptide peak areas. A similar magnitude of improvement was achieved by adopting ultrafiltration to remove the interference from GAGs with signal intensities increased an average 1.6 fold based on peptide peak areas. Comparison of the two extraction methods demonstrated compelling differences. B) A representative chromatogram of a TSP1 peptide (FVFGTTPEDILR) showed a significant improvement in the chromatogram upon sample ultrafiltration after digestion. The arrow indicates the correct transitions, which became dominant after ultrafiltration. 
A)
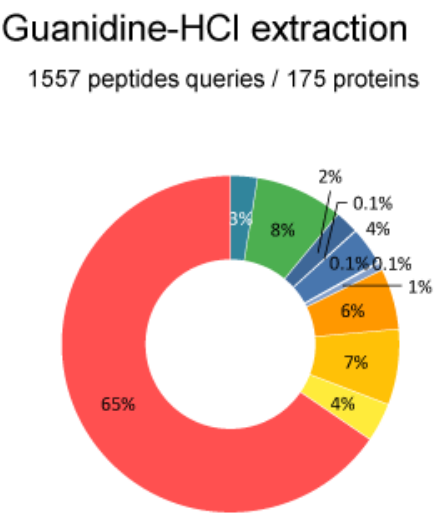

B)
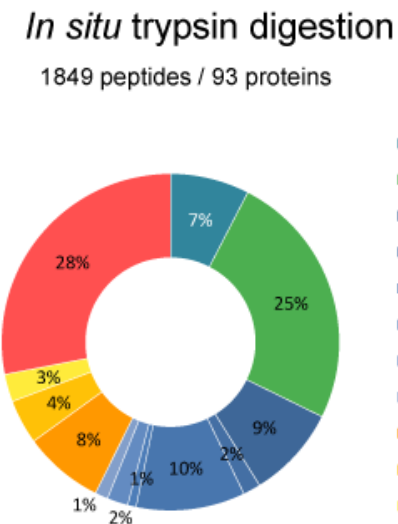

C)

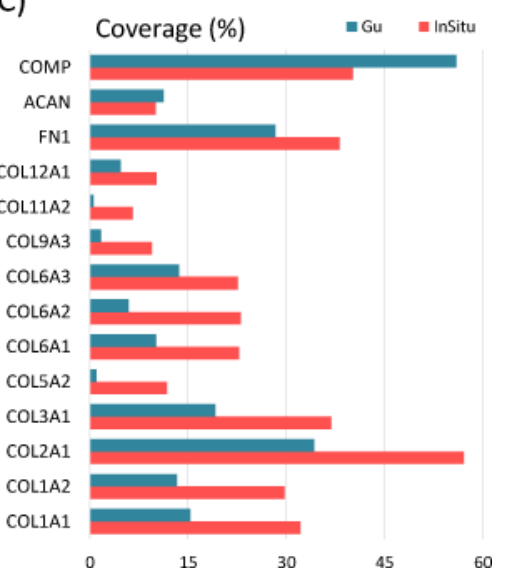

Figure 5.

Discovery proteomic analyses of decellularized cartilage sections extracted by two methods.

Discovery proteomic analysis was performed by LC-Orbitrap MS on guanidine- $\mathrm{HCl}$

extracted (A) and in situ trypsin digested (B) cartilage tissue sections (methods 1 and 2 respectively as described in Figure 2). Guanidine- $\mathrm{HCl}$ extracted cartilage yielded $17.7 \%$ collagen peptides (collagen type I, II, III, V, VI, IX, XI, XII), abundant fibronectin, aggrecan and COMP proteins, and $65.4 \%$ of peptides from other cartilage proteins present in minor amounts. The in situ digestion method yielded $57.3 \%$ collagen peptides and similar amounts of fibronectin, aggrecan and COMP compared with guanidine-HCl. However, the direct digestion method yielded only $28.1 \%$ of peptides from other more minor cartilage proteins. The peptide count by in situ digestion method reflected the predominance of the collagen superfamily of proteins within cartilage tissue. The average sequence coverage of collagen family proteins by in situ digestion versus guanidine- $\mathrm{HCl}$ extraction was $23.8 \%$ and $10.9 \%$, respectively (C). These results suggested that the in situ digestion method was not appropriate for identifying lesser abundant proteins within cartilage since the peptides from high abundant proteins generally dominated the analytical performance of the system. 


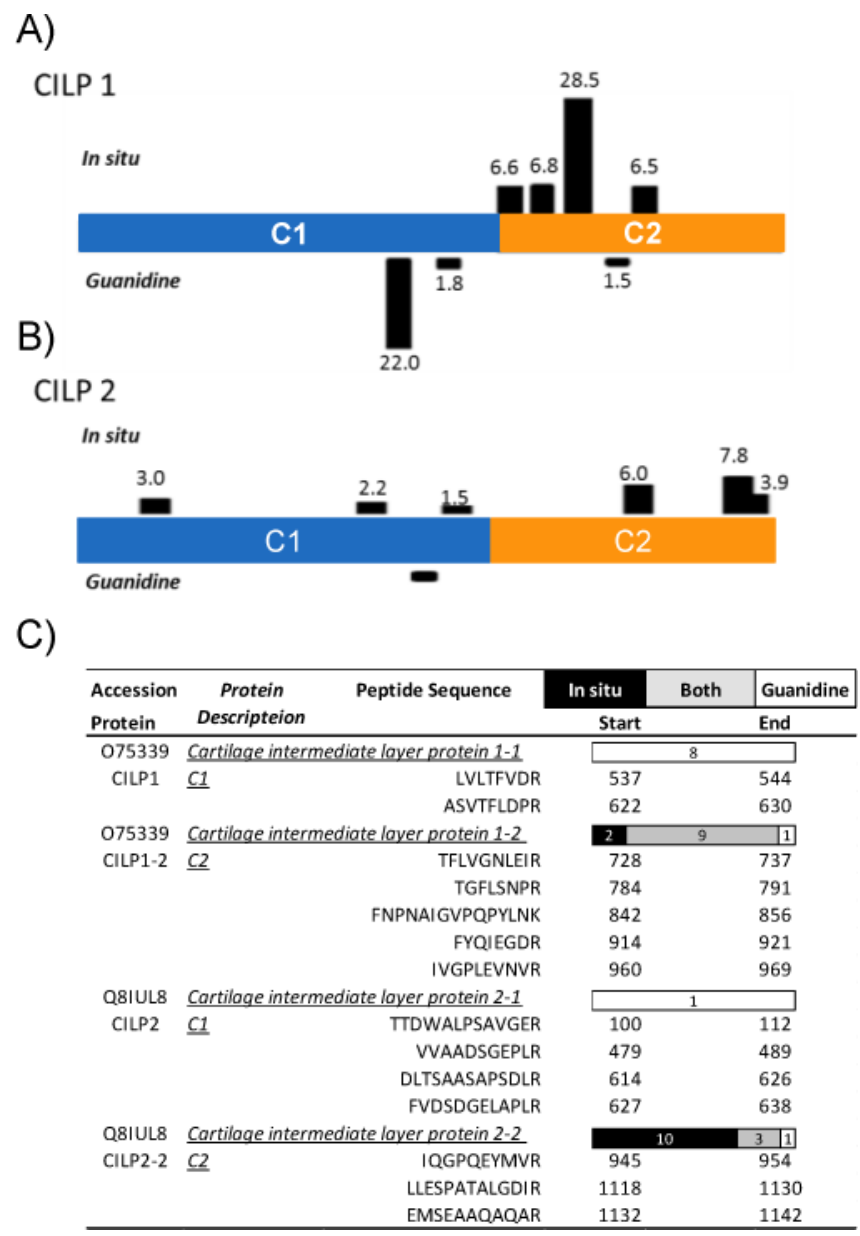

Figure 6.

Cartilage intermediate layer protein (CILP) abundance and localization demonstrated by quantitative proteomics of tissue extracted by guanidine- $\mathrm{HCl}$ and in situ digestion. The differential patterns of extraction of CILP1 (A) and CILP2 (B) by two methods were demonstrated by quantitative proteomics. Horizontal lines above and below the bars indicate the peptides identified within the protein and whether the peptides were enriched in guanidine- $\mathrm{HCl}$ extracts (lines below) or in situ digestion (lines above) extracts; the numbers associated with the lines indicate the fold enrichment of one method of extraction over the other. The horizontal bars in panel (C) summarize the numbers of peptides identified by each extraction method from only in situ digestion (black), both methods (dark gray), or only by guanidine- $\mathrm{HCl}$ (light gray). The number associated with each peptide identifies the amino acid position of the peptide quantified by MRM. 
A)

B)
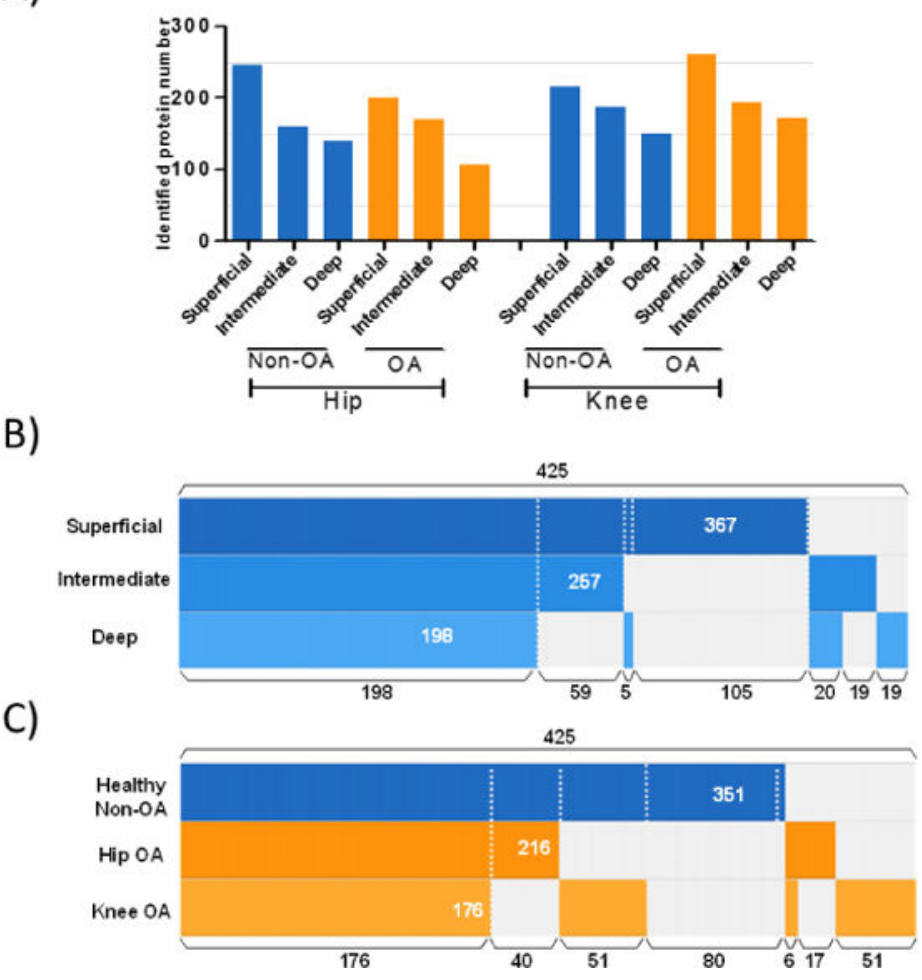

Figure 7.

Identified protein numbers and protein composition in different cartilage layers and joint types. A) By Orbitrap mass spectrometry, we analyzed cartilage tissues from knee and hip joints, both healthy non-OA and OA specimens. Sections were categorized according to the distance from the tissue surface as originating from the superficial, intermediate or deep layer. The identified protein number from each sample is depicted here. Approximately 200 proteins were identified from each sample. Overall, the superficial layer yielded the highest number of identified proteins. No significant difference was observed by joint type (hip vs knee) or disease state (non-OA vs OA). Differences in protein composition were evident comparing layers (B) and disease state and joint site (C). The numbers indicate the total number of proteins identified in each sample. Sharing of proteins across different locations or joint types is indicated by bars aligned vertically. These results suggest that a more detailed "phenotyping" of patients as well as cartilage tissue itself is necessary to precisely depict the cartilage composition of different joints. 
A)

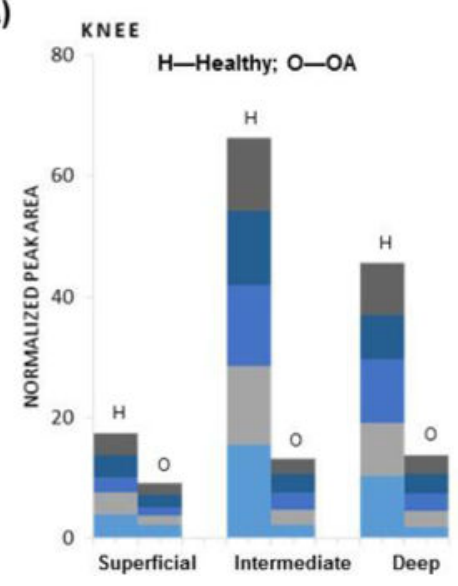

B)

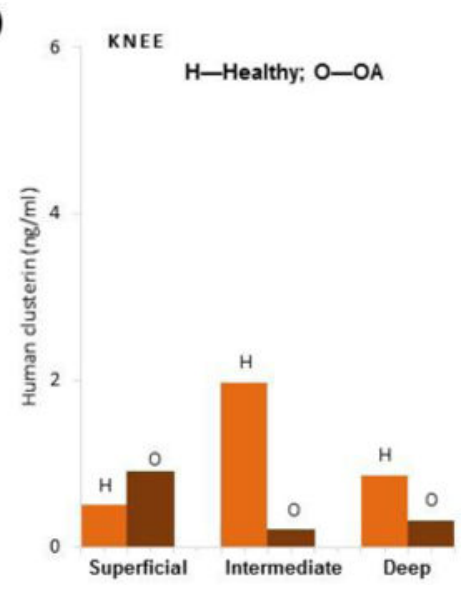

Figure 8.

Clusterin distribution pattern at different depths within knee cartilage. Clusterin distribution within different layers of cartilage from different physiological conditions determined by mass spectrometry analysis (A). Five peptides were identified within each sample and noted to behave similarly. The MS peak area of a peptide within a sample was first normalized to the section area. This value was then normalized to the sum of peak areas for this peptide in all samples and expressed as a proportion. The y-axis represents the proportion of peptide relative to the sum of the recalculated peak areas for each of 5 peptides. Each color represents a different peptide showing a striking enrichment of clusterin in the intermediate layers of the healthy knee cartilage, and to a lesser extent in the deep layer. Clusterin distribution determined by ELISA (B). Similar to the results determined by MS, clusterin content was enriched in the intermediate layer of healthy knee cartilage and also a lesser extent in the deep layer. 


\section{Table 1}

Peptide number and quantity by quantitative proteomics of cartilage extracted by guanidine- $\mathrm{HCl}$ and in situ digestion.

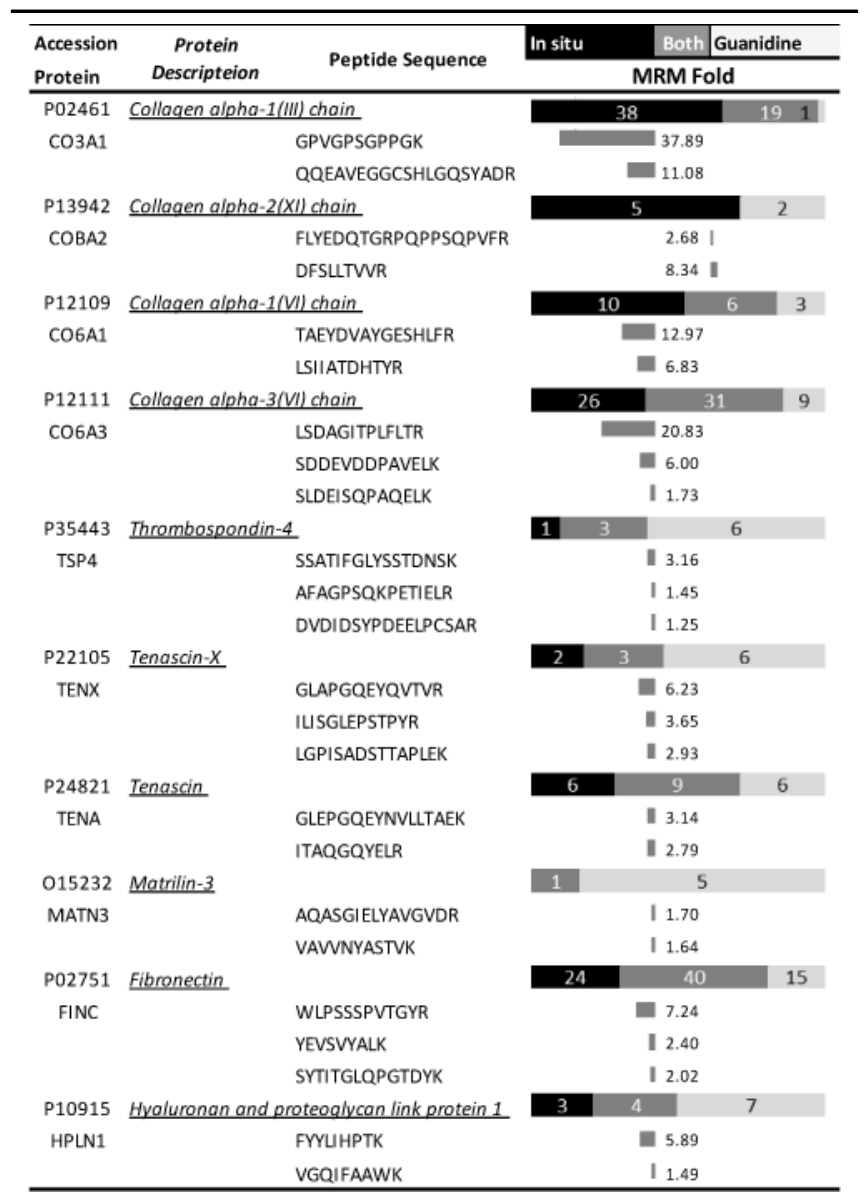

J Proteome Res. Author manuscript; available in PMC 2017 February 05. 


\begin{tabular}{|c|c|c|c|c|c|c|c|}
\hline \multirow{3}{*}{$\begin{array}{l}\text { Accession } \\
\text { Protein } \\
\text { P49747 }\end{array}$} & \multirow{2}{*}{$\begin{array}{c}\text { Protein } \\
\text { Descripteion } \\
\end{array}$} & \multirow{2}{*}{ Peptide Sequence } & In situ & & Both & Guanid & \\
\hline & & & \multicolumn{5}{|c|}{ MRM Fold } \\
\hline & \multicolumn{2}{|c|}{ Cartilage oligomeric matrix protein } & 6 & 17 & & 21 & \\
\hline \multirow[t]{4}{*}{ COMP } & & ELQETNAALQDVR & & & 1.09 । & & \\
\hline & & DTDLDGFPDE & & & $1.24 \mid$ & & \\
\hline & & SSTGPGEQLR & & & 1.851 & & \\
\hline & & LVPNPGQEDADR & & & $6.68=$ & & \\
\hline P07996 & \multicolumn{2}{|c|}{ Thrombossendin-1 } & 12 & & 17 & & \\
\hline \multirow[t]{3}{*}{ TSP1 } & & SITLFVQEDR & & & 1.021 & & \\
\hline & & FVFGTTPEDILR & & & 1.571 & & \\
\hline & & GPDPSSPAFR & & & 1.67 । & & \\
\hline P16112 & \multicolumn{2}{|c|}{ Agarecan core protein } & & & 15 & 1 & \\
\hline \multirow[t]{7}{*}{ PGCA } & & VSLPNYPAIPSDATLEVOSLR & & & $1.91 ।$ & & \\
\hline & & TIEGDFR & & & 2.011 & & \\
\hline & & YEINSLVR & & & 2.561 & & \\
\hline & & YPIVSPR & & & 2.611 & & \\
\hline & & GIVFHYR & & & 3.411 & & \\
\hline & & YTLDFDR & & & $4.58 \mathrm{I}$ & & \\
\hline & & ETWVDAER & & & 11.01 & & \\
\hline P98160 & Periecan & & & & 2 & & \\
\hline \multirow[t]{2}{*}{ PGBM } & & LEGDTUIPR & & & 1.93 & & \\
\hline & & IAHVELADAGQYR & & & 1.46 & & \\
\hline Q92954 & Proteoglycan 4 & & & 2 & & 1 & \\
\hline \multirow[t]{2}{*}{ PRG4 } & & DAGYPKPIFK & & & 1.60 & & \\
\hline & & DQYYNIDVPSR & & & 1.44 & & \\
\hline P21810 & Biglvean & & & & 14 & & 1 \\
\hline \multirow[t]{4}{*}{ PGS1 } & & WQCSDLGLK & & & 1.991 & & \\
\hline & & VPSGLPDLK & & & 2.321 & & \\
\hline & & LGLGHNQIR & & & 3.341 & & \\
\hline & & IQAIELEDUR & & & $5.60=$ & & \\
\hline P07585 & Decorin & & 2 & & 7 & & 2 \\
\hline \multirow[t]{3}{*}{ PGS2 } & & VSPGAFTPLVK & & & $1.61 \mathrm{I}$ & & \\
\hline & & NLHALILVNNK & & & 2.441 & & \\
\hline & & WACSDLGLDK & & & 7.19 & & \\
\hline Q06828 & Fibromodulin & & 2 & 3 & & 8 & \\
\hline \multirow[t]{3}{*}{ FMOD } & & YLPFVPSR & & & 1.251 & & \\
\hline & & IPPVNTNLENLYLQGNR & & & 1.661 & & \\
\hline & & SAMPADAPLCLR & & & 5.88 & 1 & \\
\hline P51884 & Lumicon & & & 6 & 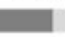 & 4 & \\
\hline \multirow[t]{3}{*}{ LUM } & & SLEDLQLTHNK & & & 3.601 & & \\
\hline & & FNALQYLR & & & $6.38=$ & & \\
\hline & & ISNIPDEYFK & & & 34.82 & 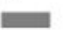 & \\
\hline Q99983 & Osteomedulin & & & & & & \\
\hline \multirow[t]{2}{*}{ OMD } & & LGYNEISK & & & 1. 67 & & \\
\hline & & IDYGVFAK & & & t. 24 & & \\
\hline P20774 & Mimecan & & 1 & 3 & 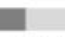 & 4 & \\
\hline MIME & & ESAYLYAR & & & 1.881 & & \\
\hline & & LEGNPIVLGK & & & 5.57 & & \\
\hline 015335 & Chondroadherin & & & 5 & 5 & & 1 \\
\hline CHAD & & SIPDNAFQSFGR & & & 1.57 I & & \\
\hline & & FSDGAFLGVTTLK & & & 1.901 & & \\
\hline & & YLETLWLDNTNLEK & & & 1.96 I & & \\
\hline & & NQLSSYPSAALSK & & & $2.78 \mathrm{I}$ & & \\
\hline Q92743 & Serine protease & & & & $\square$ & 1 & \\
\hline HTRA1 & & LPVULGR & & & 1.541 & & \\
\hline & & YNFIADVVEK & & & $4.77 \mathrm{I}$ & & \\
\hline
\end{tabular}

These results were generated by extraction using methods 1 and 2 (as described in Figure 2). The bars with enclosed numbers indicate the total number of different peptides identified by discovery proteomics from only in situ digestion (black), both methods (dark gray), or only by guanidine- $\mathrm{HCl}$ (light gray). The bars (dark gray) related to specific peptides depict the ratio (fold difference) of numbers of peptides identified by the two methods as quantified by MRM. A dark gray bar toward the left means the peptide was eniched in the in situ digestion extracts; a dark gray bar toward the right means the peptide was enriched in the guanidine- $\mathrm{HCl}$ extracts.

J Proteome Res. Author manuscript; available in PMC 2017 February 05. 


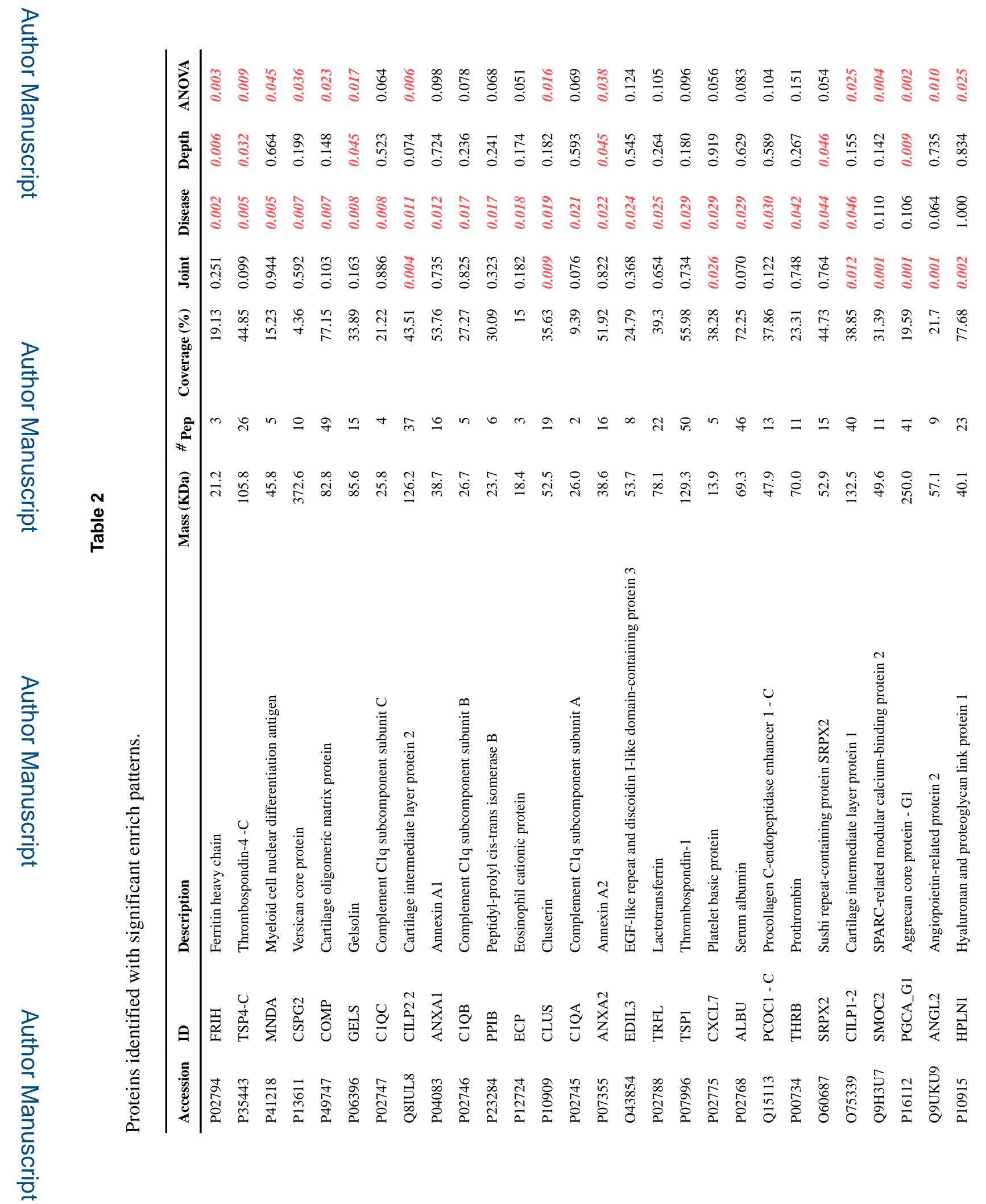

J Proteome Res. Author manuscript; available in PMC 2017 February 05. 
Hsueh et al.

Page 31

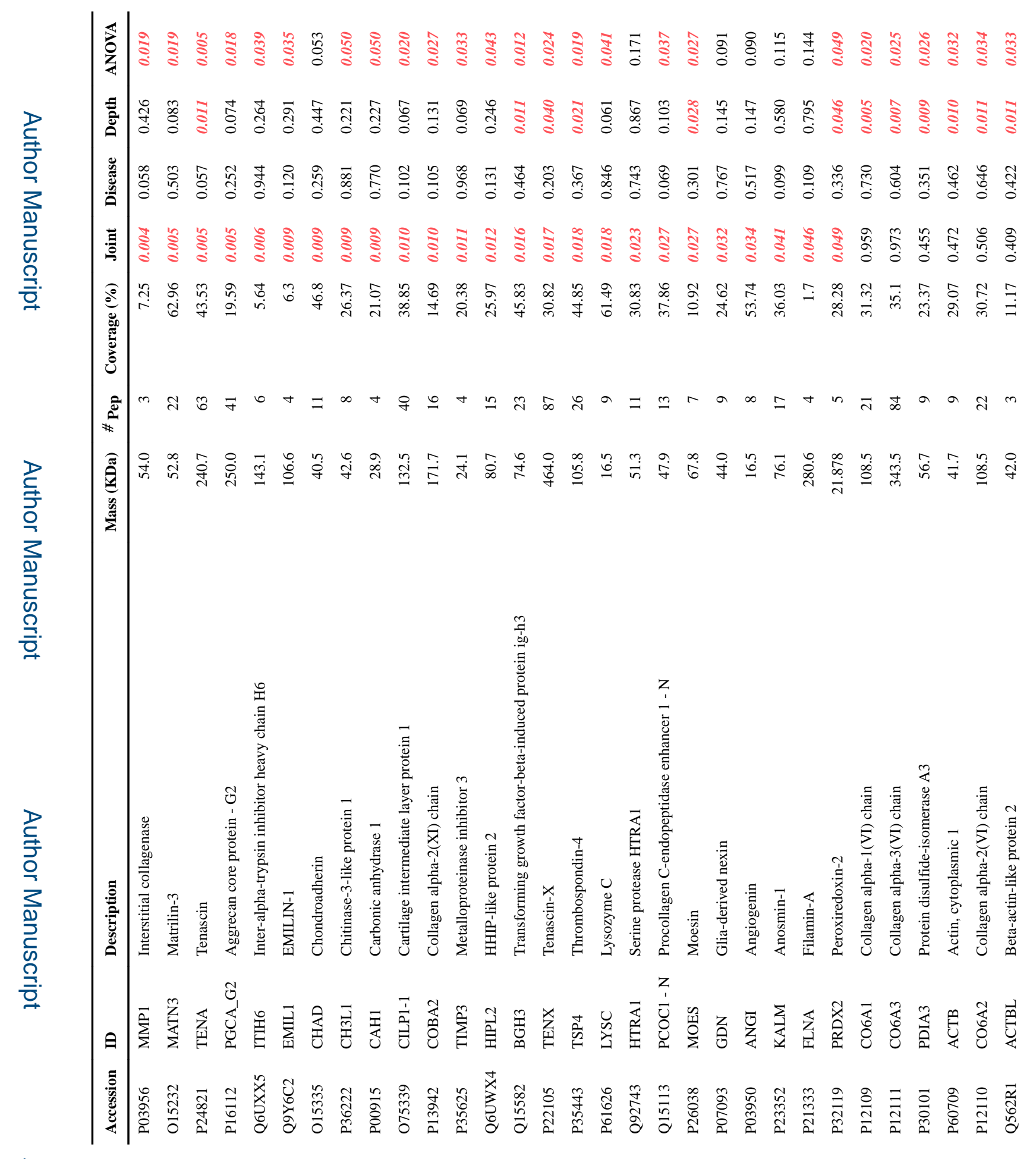

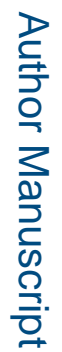

J Proteome Res. Author manuscript; available in PMC 2017 February 05. 


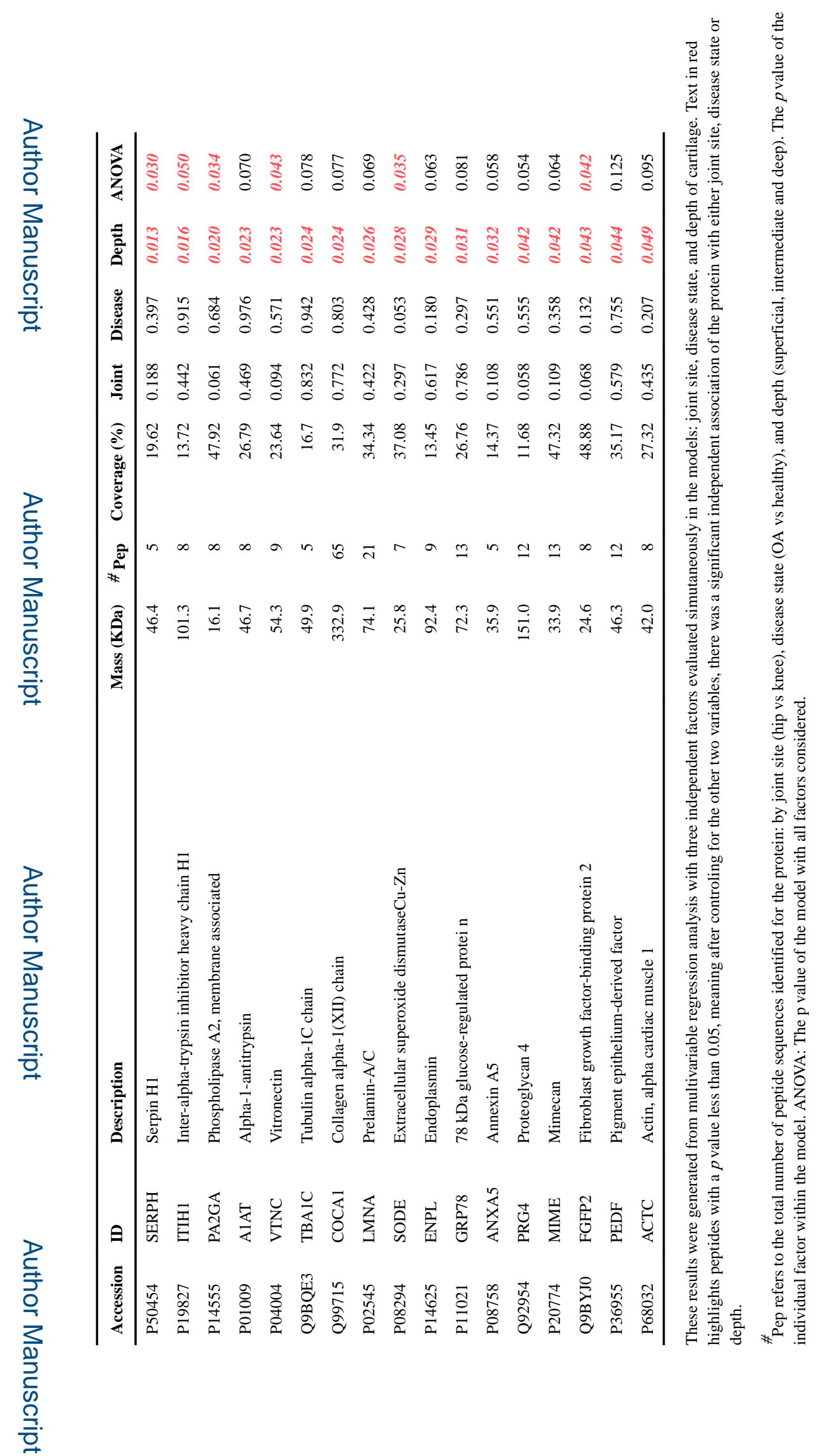

J Proteome Res. Author manuscript; available in PMC 2017 February 05. 